\title{
FCC: Fluidization Phenomena and Technologies
}

\author{
T. Gauthier' ${ }^{1}$ J. Bayle' and P. Leroy' \\ 1 Institut français du pétrole, CEDI René-Navarre, BP 3, 69390 Vernaison - France \\ e-mail: thierry.gauthier@ifp.fr
}

Résumé - FCC : phénomènes de fluidisation et technologies — Le procédé de craquage catalytique (FCC) est utilisé dans la majorité des raffineries pour convertir les charges lourdes. Depuis plus de 50 ans, les développements du catalyseur et l'amélioration de la technologie de la zone réactionnelle ont permis une évolution continue de ce procédé, évolution qui n'est sans doute pas terminée, permettant notamment de traiter des charges de plus en plus lourdes. Dans cet article, les moyens nécessaires au développement de technologies adaptées au procédé de craquage catalytique sont discutés à travers les exemples de développement d'un séparateur rapide en tête de riser et d'un échangeur de chaleur permettant de refroidir le catalyseur pendant la régénération. Les aspects liés à l'écoulement de catalyseur fluidisé à travers la zone réactionnelle sont également abordés.

Mots-clés : FCC, fluidisation, séparation, échangeur de chaleur, standpipe.

Abstract - FCC: Fluidization Phenomena and Technologies - Catalytic cracking units are present in most refineries to convert a large fraction of heavy oils. Over the last 50 years, catalyst development and improvement of the technology in the reaction zone lead to a continuous evolution, that is still going on, of this process. In this paper, $R \& D$ tools for technology are discussed through the development of riser separation systems and catalyst coolers. Catalyst circulation aspects in the reaction zone are also discussed.

Keywords: FCC, fluidization, separation, heat exchanger, standpipe. 


\section{NOTATIONS}

\section{Main Symbols}

A cross sectional area, $\mathrm{m}^{2}$

C concentration, $\mathrm{mol} / \mathrm{m}^{3}$

$D$ diameter, $\mathrm{m}$

$F \quad$ mass flow rate, $\mathrm{kg} / \mathrm{s}$

$H$ height, $\mathrm{m}$

$k \quad$ pressure drop constant

$K$ pressure drop constant

$M$ ratio of the particle mass flow rate over gas mass flow rate

$N$ number of CSTRs

$P$ pressure, $\mathrm{Pa}$

$P B$ pressure balance, $\mathrm{Pa}$

$R$ radius, $\mathrm{m}$

$Q$ volumetric flow rate, $\mathrm{m}^{3} / \mathrm{s}$

$U$ velocity, $\mathrm{m} / \mathrm{s}$

$V \quad$ superficial velocity, $\mathrm{m} / \mathrm{s}$

$W$ mass flux, $\mathrm{kg} / \mathrm{s} / \mathrm{m}^{2}$

$X \quad$ axial position, $\mathrm{m}$

$\varepsilon \quad$ holdup of a given phase

$\tau$ time constant, $\mathrm{s}$

$\rho$ density, $\mathrm{kg} / \mathrm{m}^{3}$

\section{Subscripts}

$b \quad$ related to fluidized bed conditions

br bubble velocity relative to suspension

$c$ related to cyclone

$d$ related to dipleg conditions

$d n$ related to dipleg conditions for negative pressure separators

$d p$ related to dipleg conditions for positive pressure separators

$G \quad$ related to gas flowing to the separator gas exit

$g$ related to gas

I related to inlet conditions

$i \quad$ related to intersticial gas

$m f$ related to minimum fluidization conditions

$m b$ related to minimum bubbling fluidization conditions

$p$ related to particle

$s \quad$ related to gas flowing to the separator dipleg

$s g$ related to gas for superficial velocity

sl related to slip between gas and particles

sk related to skeletal

$t$ related to tracer

tc related to tapped conditions in defluidized conditions.

\section{INTRODUCTION}

Catalytic cracking rapidly became one of the most important refining processes after it was first commercialized in 1936 by Eugène Houdry [1-6]. Over the last sixty years, continuous efforts to improve catalysts and process technology have led to the conversion of a large fraction of heavy oils $\left(360^{\circ} \mathrm{C}+\right)$ to lighter and more valuable products. Nowadays, FCC (fluid catalytic cracking) units are present in most refineries with more than 300 units in operation.

Rapid cracking reactions are favored at low pressure and high temperature. However, rapid catalyst deactivation occurs due to coke deposition on the catalyst and catalyst regeneration (controlled combustion of coke) is required. The heat produced during regeneration is consumed in the endothermic cracking reactions. FCC therefore became an integrated reaction-regeneration process where heat produced in the regeneration zone and transported by the catalyst is consumed to vaporize the liquid feed and to promote endothermic reactions (Fig. 1). This very specific characteristic implies that the catalyst flow rate in the reactor does not only depend upon the reaction requirements, but also upon the adiabatic requirements of the process. Therefore, a modification in the thermal balance of the unit can modify the catalyst circulation and the reaction zone performance. Furthermore, catalyst circulation depends upon the layout of the unit: pressure difference between the vessels, bed levels, standpipe elevation, valve design, etc.

The first developed technology proposed by Houdry was a fixed bed technology, including several fixed beds in parallel that could operate either in reaction or regeneration mode (Houdry process). A moving bed technology was later proposed [1]. In 1942, Exxon proposed the first fluid catalytic process utilizing small fluidized catalyst particles to enhance both the cracking reaction and the transport of the catalyst between the reaction and regeneration zones $[2,6]$. Over the last fifty years, several evolutions came on the market to improve the catalytic cracking process and fluidization technologies [1-6].

A schematic of the IFP-SWEC-Total [7-9] resid-cracking reaction zone ( $\mathrm{R} 2 \mathrm{R}$ process) is shown in Figure 2. Hot regenerated catalyst flows to the riser bottom. After a short preacceleration zone to stabilize the catalyst flow, it is contacted with the finely atomized feed stock. At the riser top, a riser termination device (RTD) rapidly disengages vapor products from the catalyst to reduce further thermal and catalytic cracking. The spent catalyst is degassed to remove most of the entrained hydrocarbons in a countercurrent dense phase steam stripper with multiple steam injections. Spent catalyst is then introduced on the top of the first regenerator-fluidized bed where the hot flue gas provides ultimate stripping. The first regenerator (Reg 1) acts as a mild precombustion zone to achieve 40 to $70 \%$ of the coke combustion. The partially regenerated catalyst with less 


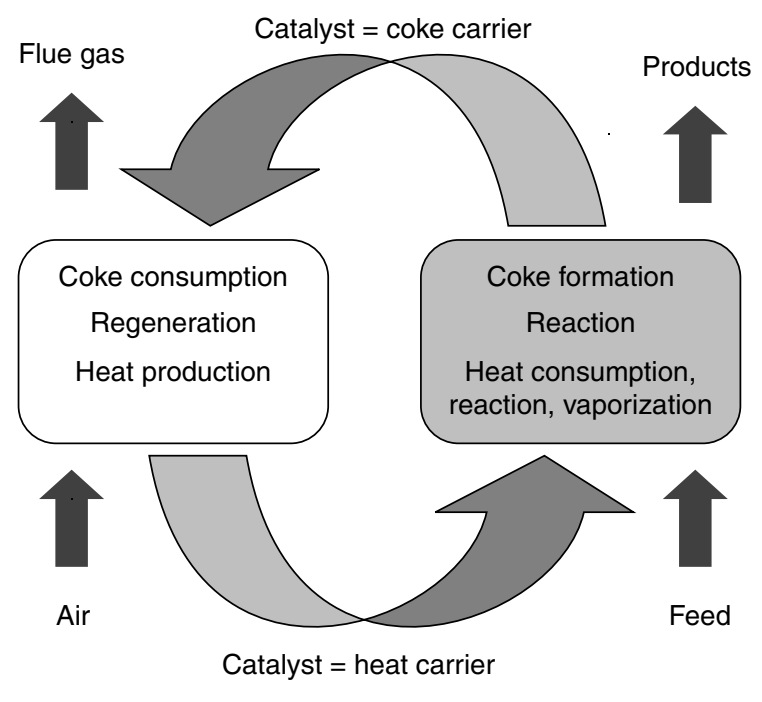

Figure 1

Reaction-regeneration integration in FCC.

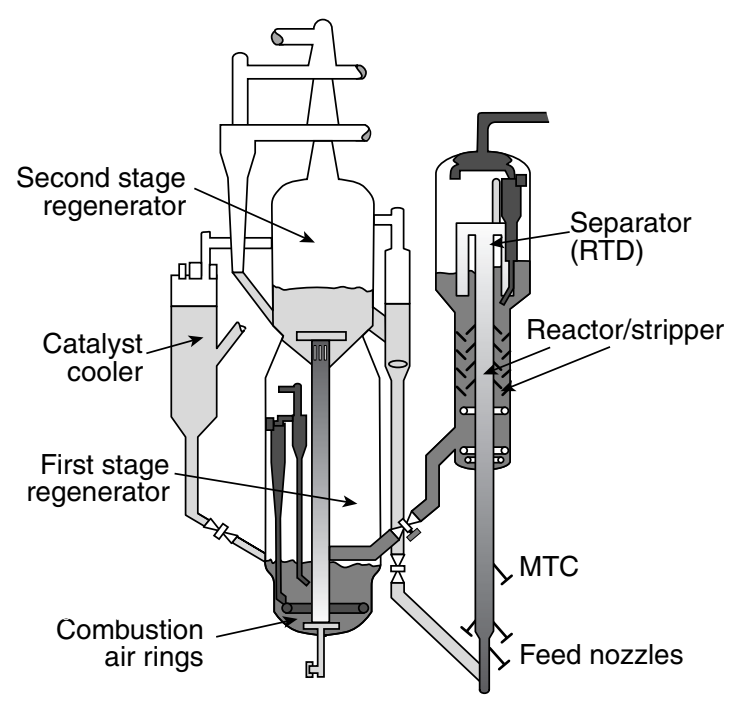

Figure 2

The $\mathrm{R} 2 \mathrm{R}$ resid fluid catalytic cracking process. than $0.5 \%$ wt coke is then air-lifted to the elevated second regenerator (Reg 2) where complete regeneration is achieved, with slight air excess and also low steam concentration in order to minimize catalyst deactivation.

Several trends still drive the evolution of the process (catalyst and technology) and lead to new developments:

- feeds: heavier feeds tend to be processed. Conventional FCC treats vacuum distillates. Progressively, refiners tend to incorporate atmospheric resids in the FCC feed or heavy secondary cuts with no value from other refining processes. With resid processes such as the $\mathrm{R} 2 \mathrm{R}$, it is now possible to convert atmospheric or even hydrotreated vacuum residues;

- product yields: depending upon the markets, the refiner may be inclined to maximize the yields of gasoline, LPG (liquified petroleum gas), propylene or even middle distillates while minimizing heavy fuel oil cuts $\left(360^{\circ} \mathrm{C}+\right)$;

- capacity and product rates: for a given unit, the refiner usually maximizes throughput or some products flow rates taking into account unit bottleneck constraints such as air blower capacity, regeneration temperature, wet gas compressor capacity or gas plant capacity;

- product quality and emissions: sulfur in liquid products, olefinicity of LPGs or gasoline, polyaromatics in middle distillates or $\mathrm{SO}_{\mathrm{x}}$ (sulfur oxides), $\mathrm{NO}_{\mathrm{x}}$ (nitrogen oxides) and dust emissions in flue gas.

When new developments are proposed, reliability is required to allow long-term operation between maintenance shutdowns (every 3-5 years typically). As much as $4000 \mathrm{t} / \mathrm{h}$ of hot catalyst is transported in the FCC system at up to $20-30 \mathrm{~m} / \mathrm{s}$, thereby requiring a robust process and mechanical design. Good unit operation and performance must be achieved to justify the refiner's investment and to minimize short payout times imposed by business aspects.

In the field of technology, new developments require a good understanding of relevant phenomena to properly extrapolate at very large scale (about 30 to $50 \%$ of the refinery feed flows through the FCC, feed flow rate range typically between 3000 to $15000 \mathrm{t} / \mathrm{d}$ ). In fluid catalytic cracking, most of the relevant phenomena are associated with the fluidization and transport of the catalyst which circulates at very high rates (typically 15000 to 100000 t/d). FCC catalyst is a polydispersed $\mathrm{Si}-\mathrm{Al}$ with the following properties $\left(d_{s v}=55-80 \mu \mathrm{m}, \rho_{s k}=2600 \mathrm{~kg} / \mathrm{m}^{3} \rho_{p}=1200\right.$ $1700 \mathrm{~kg} / \mathrm{m}^{3}$ ). This powder has typical Group A properties according to Geldart's classification. Numerous academic studies have been conducted since the beginning of FCC development. However, it is still difficult to theoretically predict gas-particle interactions during transport or bubble formation in fluidized beds. It is therefore often required to combine experiments at various scales with modeling in order to develop and scale up new technologies. Fundamental research is still needed to improve understanding of basic fluidization and transport phenomena. In this paper, we take examples of some development studies (riser separation, catalyst cooler, catalyst circulation and flow modeling) in order to discuss the tools that can be used to properly understand phenomena, to scale up technologies and to improve basic knowledge in fluidization and transport. 


\section{RISER SEPARATION}

Over the last fifteen years, rapid riser termination became an important issue [10]. Previously, the reaction zone was designed with simple riser disengagement (an example is shown in Figure 3a). Hydrocarbon products and catalyst were roughly separated in a simple inertial device located at the riser top. The catalyst was directed downward toward the stripping zone in the dilute phase while hydrocarbon products rose in the dilute phase to the reactor cyclones (either one or two stages) for final catalyst separation. Depending upon riser and separator as much as reactor design, post riser residence times for the hydrocarbons in the reactor dilute phase were typically $15-45 \mathrm{~s}$, which was significantly larger than the contact time in the riser (typically 1-5 s).

Hydrocarbons can be thermally degraded if they are exposed to high temperature for long times. Furthermore, significant amounts of catalyst in the dilute phase can promote catalytic post riser cracking and subsequent uncontrolled overcracking. Ways to limit post riser thermal degradation and overcracking were therefore investigated and proposed. Several factors may explain this evolution:

- in order to increase olefin production or conversion, the reaction temperature can be increased up to $550^{\circ} \mathrm{C}$ or more. But, in those conditions, thermal degradation increases rapidly;

- thermal degradation and overcracking lead to higher volumetric flow rates of gas. Many units have bottlenecks in the gas plant at the wet gas compressor. A reduction of gases obtained by limitation of post riser reactions gives the possibility to increase the overall unit capacity without changing this costly equipment.

In order to limit post riser reactions, the disengagement of gas and catalyst was improved at the riser outlet, leading to new riser separators, forcing catalyst into the stripping zone through diplegs and hydrocarbon vapors to the upper portion of the dilute phase close to reactor cyclones. Depending upon design, hydrocarbon vapors discharge either in the upper dilute phase (Fig. 3b) or in the reactor cyclone inlets (Fig. 3c). Another option to further suppress thermal degradation is the injection of recycle liquids into the vapor after primary catalyst separation to quench the reaction.

To address this evolution, several points need to be addressed, among which:

- particle collection efficiency: the separation system must properly separate gas and catalyst in wide ranges of velocities and catalyst loadings from start-up to normal operation;

- gas efficiency: most of the vapors need to be directed in the vapor outlet tube and the gas entrained to the diplegs (called underflow) needs to be minimized;

- effect of the riser termination on the riser hydrodynamics;

- dipleg hydrodynamics, dipleg length and immersion in the stripper fluidized bed;

- dilute phase hydrodynamics;

- space available in between reactor cyclones and mechanical assembly of the separator;

- thermal expansion in the reactor depending upon the way riser, separators and reactor cyclones are connected.

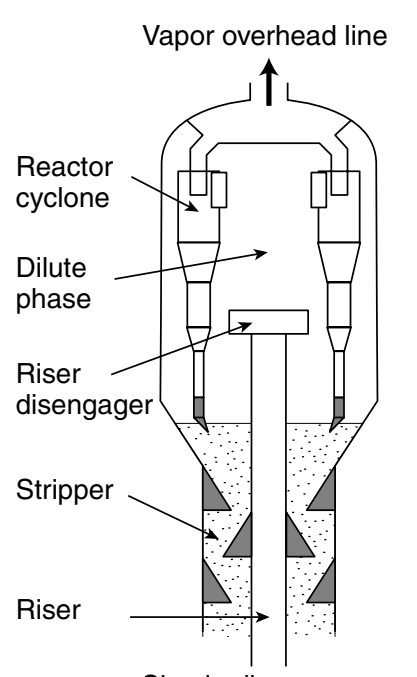

a Simple disengagement

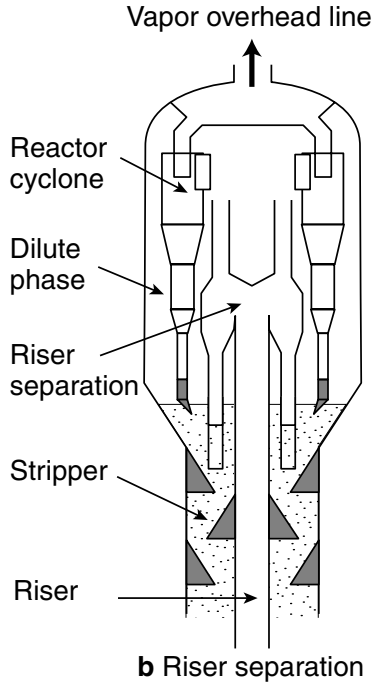

b Riser separation

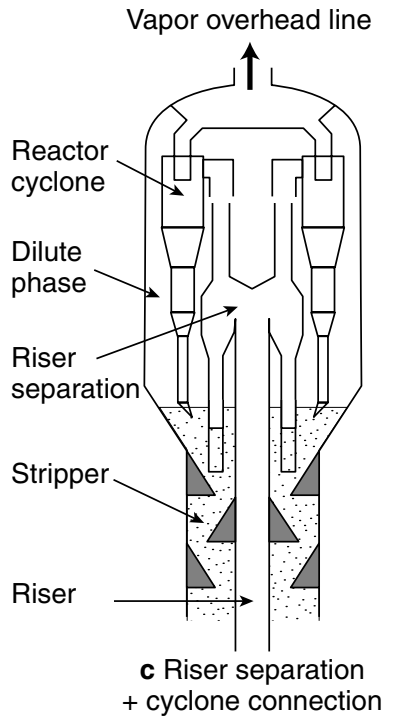

Figure 3

Riser termination and reactor design evolution. 


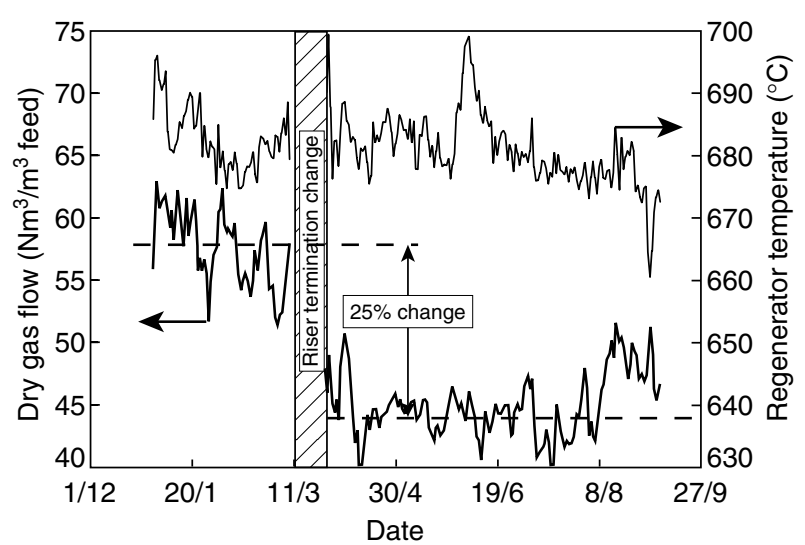

Figure 4

Dry gas flow evolution with RTD configuration change.

The modification of the riser termination can induce dramatic changes in unit performance. In Figure 4, we plotted dry gas flow rates produced related to feed rates before and after such a modification on an industrial unit (in the present case, the riser termination was the only change conducted). The change lead to about $25 \%$ decrease in dry gas flow rates after the improvement. Therefore, the refiner could increase the unit throughput significantly with subsequent benefits.

One of the main differences between riser separation systems and conventional cyclones is that, for most applications, the riser separation system is at a higher pressure than the surrounding reactor. In Figure 5, two identical cyclones are represented in a fluidized bed vessel. The left cyclone is fed from the dilute phase of the bed. Due to inlet acceleration and cyclone pressure drop, the cyclone barrel is at a pressure lower than the dilute phase. As a consequence, a suction of catalyst occurs at the dipleg discharge and a dense phase establishes in the dipleg. The cyclone on the right is fed by an external transport line. It discharges gas in the dilute phase through the gas exit pipe. The cyclone barrel is therefore at a higher pressure than the dilute phase. If a dense phase forms in the dipleg, its height should establish below the bed level, as shown in Figure 5. The left cyclone is called a negative pressure separator and the right cyclone a positive pressure separator. Reactor cyclones and regenerator cyclones behave like negative pressure cyclones. Most of the riser separation systems are positive pressure separators.

If acceleration and deceleration are neglected at cyclone inlets and outlets, it can be shown that for a given operation, the level difference of dense phases in both cyclones is proportional to the cyclone pressure drop $\Delta P_{c}$ (pressure difference from gas inlet to gas outlet):

$$
\rho_{d} \mathrm{~g}\left(H_{d n}-H_{d p}\right)=\Delta P_{c}
$$

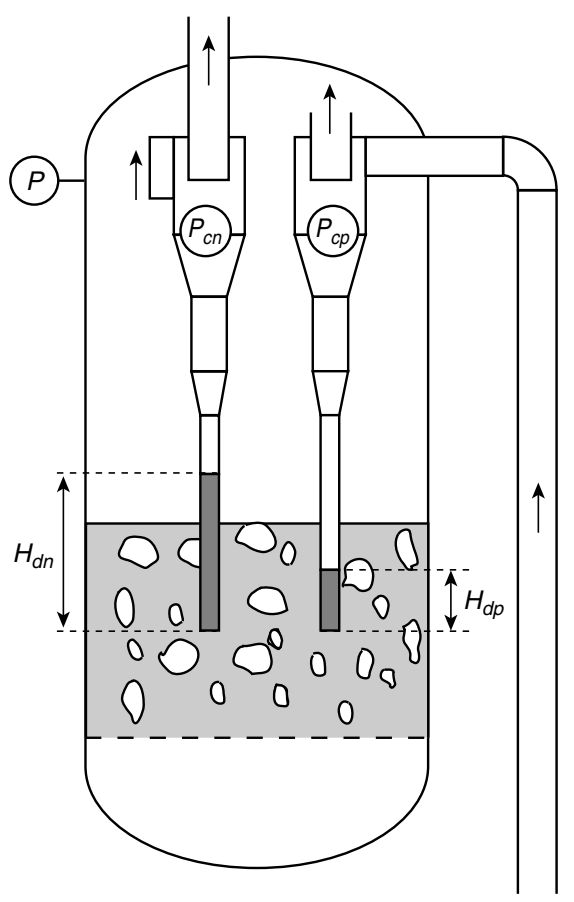

Figure 5

Negative and positive cyclones.

A dense phase buildup is a good way to limit gas flow in diplegs for positive separators. Only interstitial gas in the dense phase can then migrate to the fluidized bed. However, to get a dense phase, it is necessary to immerge the dipleg in the bed deep enough. If the dipleg immersion in the bed is not sufficient, no dense phase will build up and dilute catalyst flow with a lot of gas will flow through the dipleg to the fluidized bed.

In order to validate dipleg hydrodynamics and pressure balance mechanisms, cold flow testing was conducted on a large cold flow model [11]. Figure 6 describes the experimental setup. The riser separator (RTD) is inserted on top of a $0.123 \mathrm{~m}$ ID riser where gas and catalyst flow rates can be adjusted independently. The dipleg of the separation system is connected to a large fluidized bed; particles are recycled at the riser bottom. The bed level can be modified relative to the dipleg connection point. The gas exit of the separation system discharges in the dilute phase of another fluidized bed. Both fluidized beds can be independently pressurized to exert different pressure balances on the separator.

A few separation systems were tested in the loop with the following objectives:

- evaluating collection efficiency in a wide range of operating conditions;

- evaluating pressure balance effect on gas flow repartition in between gas and particle exits. 


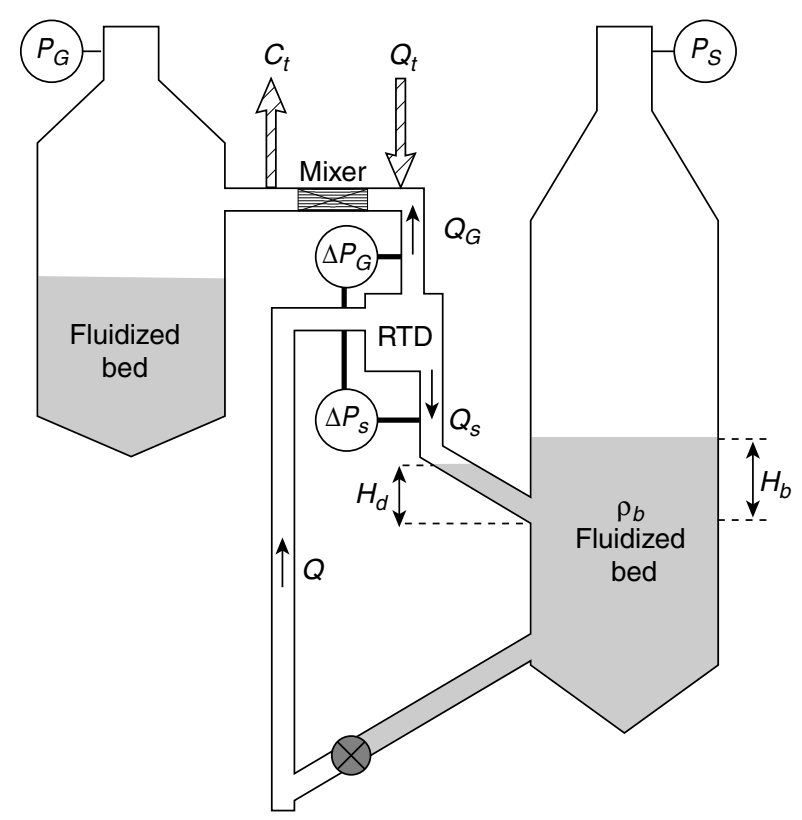

Figure 6

Cold flow testing setup.

Collection efficiency was measured by pseudo-isokinetic sampling in the gas exit. For most separators, extremely high collection efficiencies (above 98\%) were measured on the test loop.

In order to evaluate gas flow repartition, two experimental methods were used:

- a known flow rate $Q_{t}$ of tracer was injected in the gas exit duct. After intense mixing, gas was sampled downstream and the gas flow rate in the gas exit could be related to the measured tracer concentration $C_{t}$ (Fig. 6);

- after a few experiments, it was found that the pressure drop between the riser separator inlet and the gas exit duct $\Delta P_{G}$ (Fig. 6) depends essentially upon kinetic energy dissipation of the gas volumetric flow rate $Q_{G}$ in the gas exit duct:

$$
\Delta P_{G}=k_{G} V_{G}^{2}=K_{G} Q_{G}^{2}
$$

Furthermore, the pressure drop was found to be independent of the catalyst flow in the conditions of the test, which is probably inherent to the type of separation systems tested here.

The dissipation constant $K_{G}$ was then determined for each separation system by a separate experiment in which the dipleg was plugged to calibrate the pressure drop $\Delta P_{G}$ as a function of the riser gas flow rate. During experiments, it was thus possible to determine the amount of gas flowing in the gas exit duct by recording $\Delta P_{G}$.

Both ways of measuring the gas flow repartition were found to be consistent and allowed to evaluate the underflow $U$, defined as the proportion of gas flowing to the dipleg:

$$
U=1-\frac{Q_{G}}{Q}
$$

Figure 7 shows that the underflow determined by pressure drop measurement is within $10 \%$ equal to the underflow determined by the tracer on a wide range of conditions. For given gas and catalyst flow rates, the pressure balance around the riser separator could be modified either by changing the pressure difference $P_{S}-P_{G}$ between the two fluidized beds, or by changing the dipleg immersion $H_{b}$ in the fluidized bed (Fig. 6).

The test loop experiments showed that a modification of the riser separator pressure balance can lead to drastic changes in the gas flow repartition between gas exit and dipleg, as shown in Figures 8 and 9 for a given separation system. Underflow is plotted as a function of the riser separator's pressure balance $P B$ that represents the counterpressure exerted on the dipleg relative to the separator's gas exit:

$$
P B=P_{s}+\rho_{b} \mathrm{~g} H_{b}-P_{G}
$$

In industrial conditions, $P_{G}$ equals $P_{S}$ and the pressure balance would only depend upon the dipleg immersion $H_{b}$.

In Figure 8, the pressure balance effect on flow repartition is shown for various catalyst to gas mass flow ratios $M$ ranging from 0 to 7 with a fixed gas inlet velocity of $21 \mathrm{~m} / \mathrm{s}$. If the pressure balance is negative enough (counterpressure exerted on the gas exit), most gas flows through the dipleg, underflow tends to $100 \%$. On the other hand, if enough counterpressure is exerted on the dipleg $(P B>>0)$, then underflow tends to $0 \%$ and a dense phase formation is possible. When $P B$ equals 0 (Fig. 8), which corresponds to the situation of an industrial riser separator discharging in the dilute phase with unsubmerged diplegs, underflow is intermediate. Generally, underflow reduces while increasing catalyst circulation but remains around 30\% when no counterpressure is applied to the dipleg. For the separation system considered, it was necessary to get $P B=60 \mathrm{hPa}$ to minimize underflow $(U=0 \%)$ in the dipleg, which corresponds here roughly to about $1 \mathrm{~m}$ of dipleg submergence in the fluidized bed.

Figure 9 highlights the effect of gas inlet velocity, ranging from 5 to $21 \mathrm{~m} / \mathrm{s}$, with a constant catalyst mass flux of $185 \mathrm{~kg} / \mathrm{s} / \mathrm{m}^{2}$. When inlet velocity decreases, the counterpressure to be applied to minimize underflow strongly decreases from about $60 \mathrm{hPA}$ to less than $4 \mathrm{hPa}$ due to the reduction of the pressure drop in the riser separator which depends on the square of the velocity.

A simple pressure balance model was developed in order to understand and predict flow repartition as a function of operating conditions. This model is described in Appendix A. As shown in Figures 8 and 9, an excellent agreement is obtained between model and experiments. 


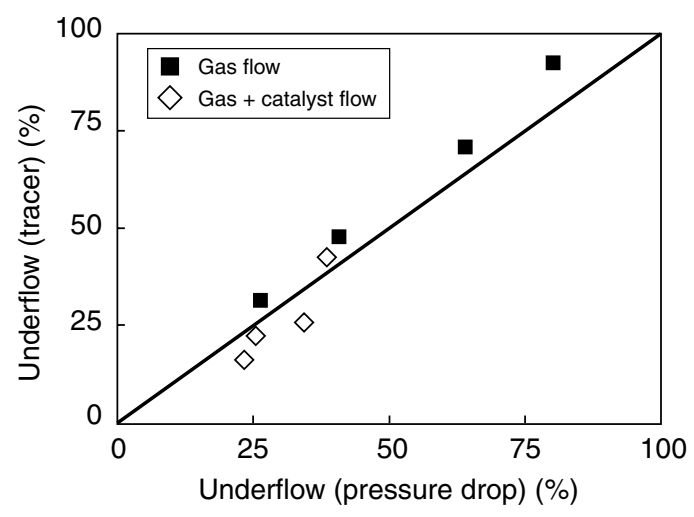

Figure 7

Comparison of underflow results determined by pressure drop or tracer measurements.

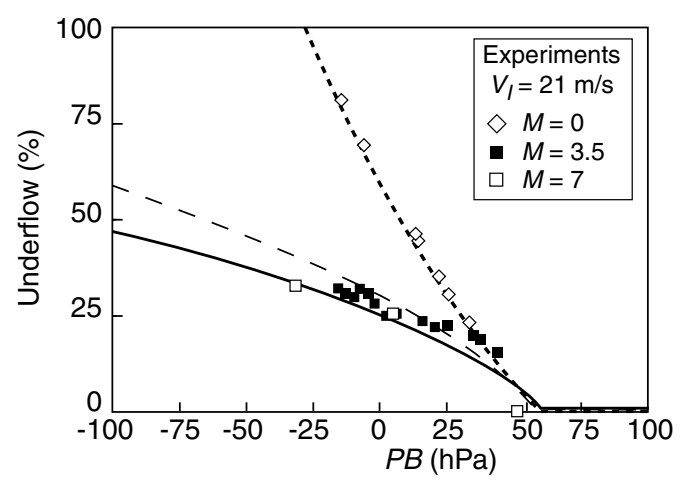

Figure 8

Effect of pressure balance on the flow repartition at $V_{I}=21 \mathrm{~m} / \mathrm{s}$ for a given RSS at various catalyst to gas mass flow ratios $M$.

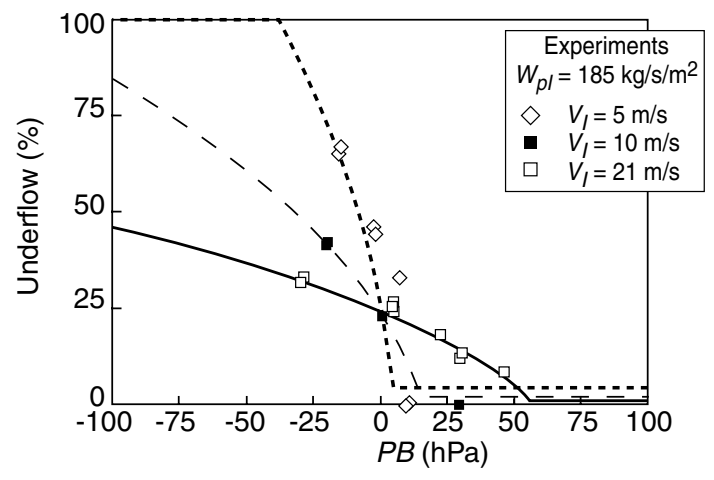

Figure 9

Effect of pressure balance on the flow repartition at $W_{p I}=185 \mathrm{~kg} / \mathrm{s} / \mathrm{m}^{2}$ for a given RSS at various gas inlet velocities $V_{I}$.
The model clearly shows that in order to get the minimum amount of underflow, the counterpressure exerted on the dipleg must be equal or exceed the separator pressure drop $\Delta P_{G}$ (Appendix $A$ ). For design purposes, the riser separator pressure drop has to be minimized in order to limit dipleg immersion requirements and to keep the possibility to operate the unit either with submerged or unsubmerged diplegs for practical reasons:

- gas underflow promotes collection efficiency. During unit start-up, unsubmerged diplegs leading to underflow will promote good collection efficiencies, even at low gas velocities;

- the variations of the stripper fluidized bed level are limited by the unit pressure balance;

- if the catalyst is introduced very deep in the stripper, stripping may be altered.

Computational fluid dynamics (CFD) was used to optimize the riser separator geometry in order to minimize pressure drop. 3D gas flow simulations were undertaken. An example of gas velocity field is shown in Figure 10 for a given geometry. This effort lead to a decrease in the separation system pressure drop by more than $75 \%$. The best geometries were then tested again on the cold flow loop (Fig. 6). CFD was further used to evaluate the variation of pressure drop due to scale-up in industrial conditions.

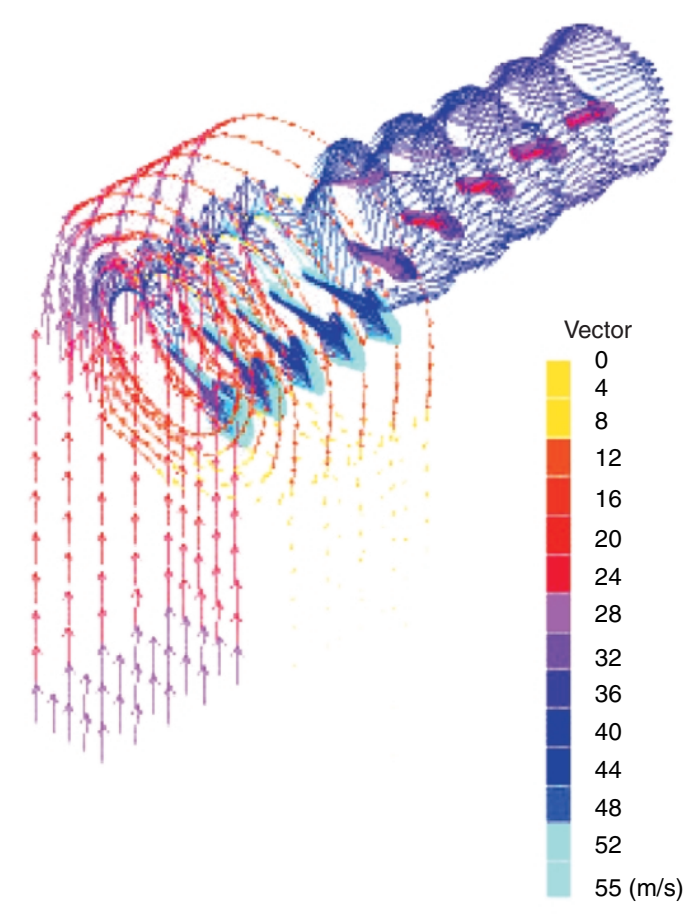

Figure 10

Exemple of gas velocity field obtained by CFD simulation. 
The pressure balance model proposed in Appendix A enables to compute underflow as a function of the separator pressure balance. When enough dipleg submergence is provided, underflow is minimized and does no longer depend upon the pressure balance. A dense phase forms in the bottom of the dipleg in order to absorb the pressure balance in excess at the dipleg bottom.

Diplegs of riser separators have high circulation rates (essentially all of the riser circulation). When a dense phase forms to absorb excess counterpressure, diplegs essentially act as standpipes. The flow regimes are then essentially dependent upon the catalyst velocity in the dipleg. For Group A powders such as FCC catalyst, gas can flow either in bubbles or in the emulsion phase. Bubbles have a rise velocity relative to the surrounding emulsion phase. If the emulsion phase downward velocity exceeds the bubble rise velocity, then bubbles are entrained downward. On the other hand, if the emulsion phase downward velocity is smaller than the bubble rise velocity, then bubbles rise in the emulsion.

It was possible to visualize dense dipleg flow in a Plexiglas cold flow model at various catalyst mass fluxes in conditions where underflow was minimized by a deep dipleg submergence. In Figure 11, we show pictures of the dipleg top at low mass flux (about $80 \mathrm{~kg} / \mathrm{s} / \mathrm{m}^{2}$ ) and high mass fluxes $\left(250-500 \mathrm{~kg} / \mathrm{s} / \mathrm{m}^{2}\right)$ in cold flow conditions. At low mass flux (Fig. 11a), the catalyst flow is slow enough to limit bubble downward entrainment. The top of the dense phase is clearly visible. There are no pockets of gas in the dense phase. At high mass flux (Fig. 11b), a lot of gas pockets are clearly visible in the dense phase: they form at the dipleg entrance, captured by catalyst strands falling from the separator. The high velocity of those strands sucks the bubbles downward. As a consequence, the dense phase density decreases when the solid mass flux increases and more gas is entrained downward. Hence, hydrocarbons enter deep in the stripper bed. Figure 12 shows bubbles discharging in the fluidized bed at high mass fluxes. On industrial units, excess entrainment of hydrocarbons deep in the dense phase stripper may lead to an increase of coke formation and have detrimental consequences on the heat balance of the process. The dipleg flow therefore needs to be controlled in order to limit hydrocarbon entrainment through the diplegs when they are submerged in the stripper fluidized bed.

It was possible to verify those phenomena by conducting a radioactive tracer campaign on an industrial FCC unit. More than twenty detectors were placed at various elevations and chords through the riser and reactor on a unit equipped with an older riser termination system that had been characterized during cold flow testing (Fig. 13). Argon 41 was injected with the atomization steam through the feed nozzles to trace the gas phase. During this campaign, several unit parameters were varied, among which feed flow rate and stripper bed level, to modify the separator pressure balance.

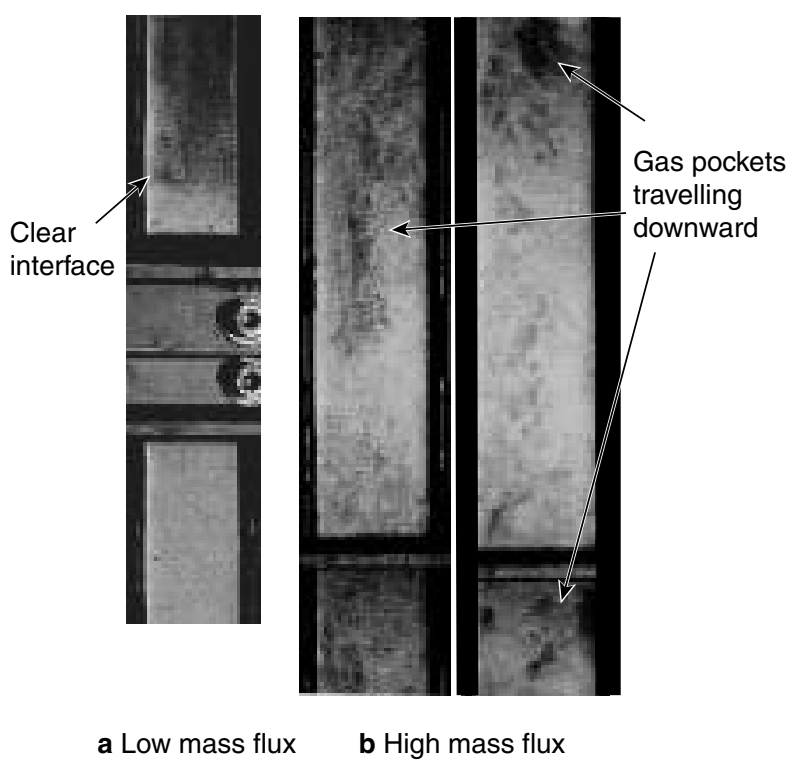

Figure 11

Top dipleg flow with a dense phase.
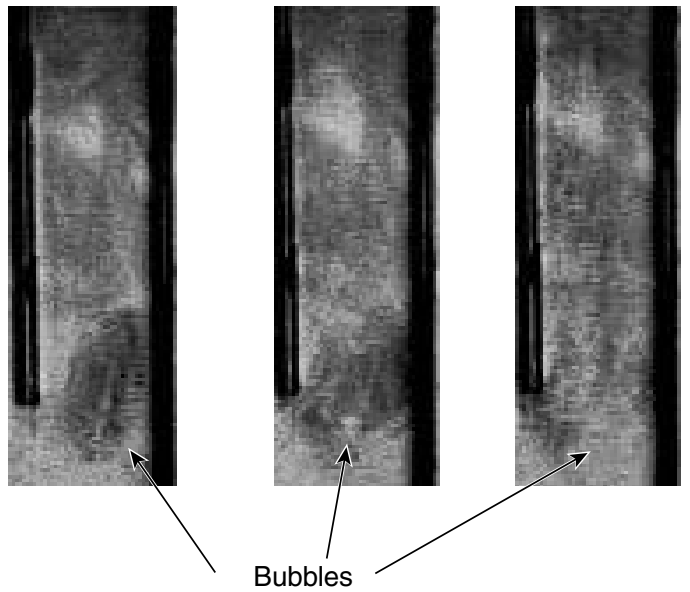

Figure 12

Bottom dipleg flow with a dense phase at high catalyst mass flux.

In order to optimize the location of the detectors around the reactor vessel, tracer injections were simulated with a commercial software (DTS from Progepi, Nancy, France). A flow model consisting of an assembly of flow boxes with specific characteristics (plug flow, CSTR-continuous stirred tank reactor-, $N$ CSTRs in series) was built (Fig. 14). The constants of each flow boxes (time constant $\tau$ and $N$ ) were determined based on actual unit geometries and flow rates. Figure 15 shows simulations of the vapor overhead line response when the dipleg is not immersed in the stripper bed, for various underflow hypothesis from 20 to $50 \%$ corresponding to expected underflows in such conditions. 


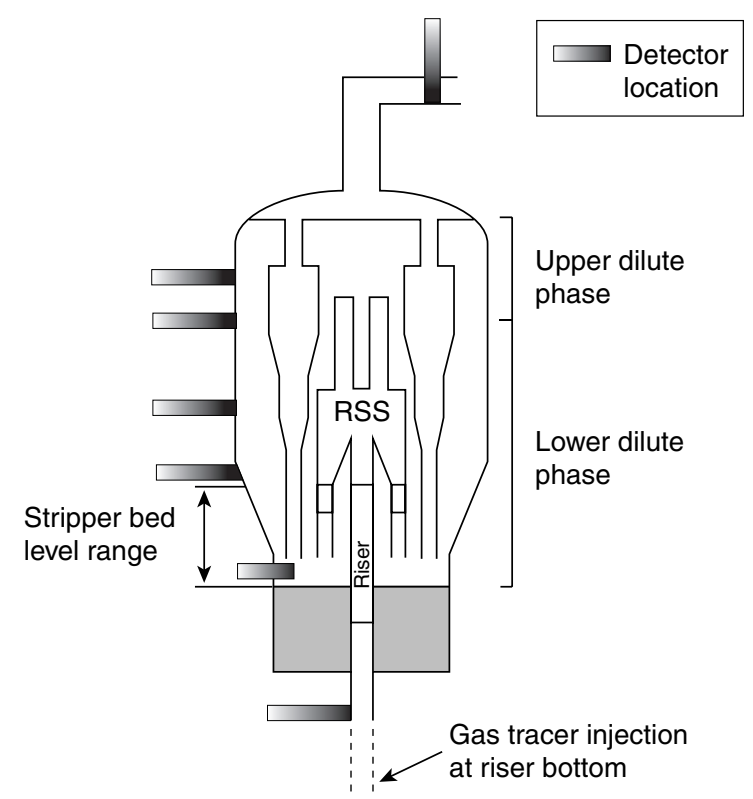

Figure 13

Radioactive tracer work on an industrial unit.

According to the simulations, a first peak, corresponding to the flow of vapor through the riser separator gas exits, should be rapidly observed, followed by a second peak with a longer tail, whose height and position relative to the first peak depend upon the underflow rate. This second peak corresponds to underflow gas first flowing downward through the diplegs and then upward through the dilute phase to the cyclones.

Figure 16 gives an example of an actual vapor overhead line response corresponding to the simulation conditions of Figure 15 when the diplegs are unsubmerged. As expected, two peaks are detected. The model (Fig. 14) was used to determine underflow by best fit adjustment of the experiment with the model response. The underflow rate could be further confirmed by analyzing the detector responses along the dilute phase in between dipleg discharge and gas exit as a function of time (Fig. 17). An underflow rate of 40 to $50 \%$ was then consistently determined for those unsubmerged conditions without dipleg counterpressure.

All the tools used in this development (cold flow testing, CFD) lead to consistent conclusions concerning the relevant phenomena to be addressed, which were later confirmed by industrial unit observations. The main concepts to be respected were clearly established:

- minimizing riser separator pressure drop to maximize pressure balance flexibility;

- minimizing the dipleg catalyst mass flux.

The schematics of the compact riser separator system (RSS) resulting from the development studies and commercially proposed is shown in Figure 18. This separator consists of a compact arrangement of separation chambers around the riser. In between separation chambers, the space is used to properly evacuate riser vapors and stripping gas to the reactor cyclones in controlled conditions.

\section{CATALYST COOLER}

Very heavy FCC feedstocks tend to produce high coke yields that may cause heat balance problems even for two-stage regeneration units such as $\mathrm{R} 2 \mathrm{R}$. Therefore, in some cases, additional heat removal facilities are required. An R2R unit can successfully process feeds containing up to about $6 \% \mathrm{wt}$ Conradson carbon (Con $\mathrm{C}$ ), which is a feed property directly related to the coke production. Above $6 \%$ Con $\mathrm{C}$, consideration must be given to external additional means of cooling. Two very effective options include:

- cooling the riser with mix temperature control (MTC) by injection of recycle liquid $[12,13]$;

- utilizing a catalyst cooler (heat exchanger implemented in the regeneration section) [13].

The choice is predicated on several factors [13], including high-pressure steam value and continuity of high Con $\mathrm{C}$ operation. Adding MTC at a rate of $25 \%$ fresh feed enables an R2R unit to process feeds as high as 7 to $7.5 \%$ Con C. For heavier feeds, or when high-pressure steam is valuable, a catalyst cooler may be justified in addition to the conventional R2R technologies.

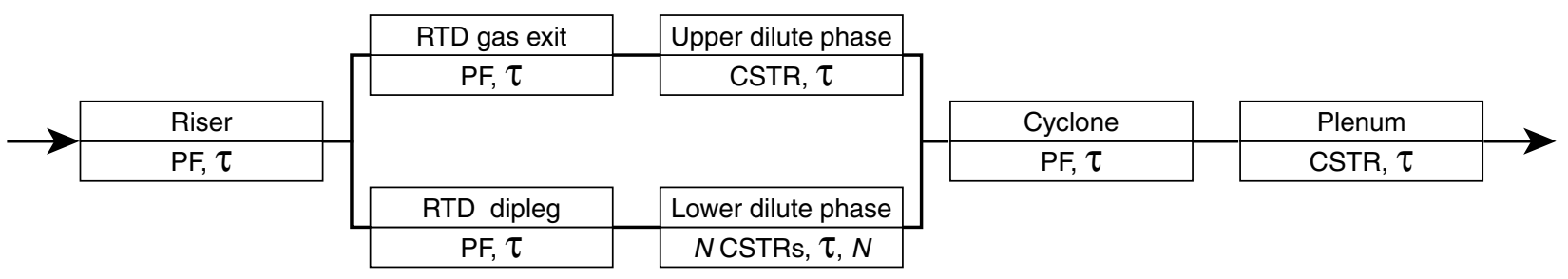

Figure 14

Reactor flow model assembly for RTD studies. 


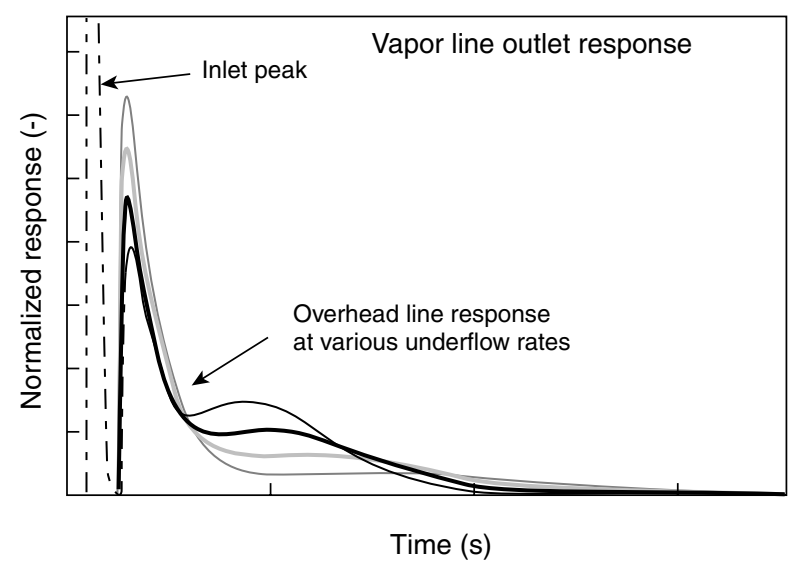

Figure 15

Simulation of the outlet response for various underflow cases.

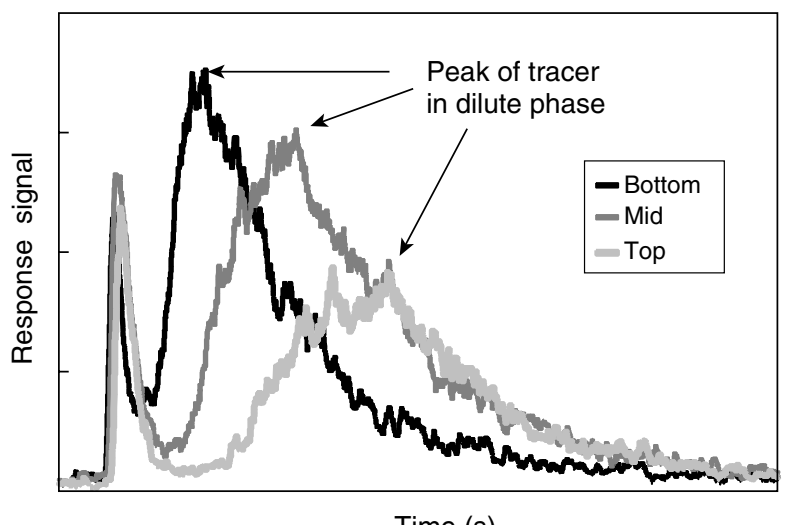

Figure 17

Side reactor vessel detection.

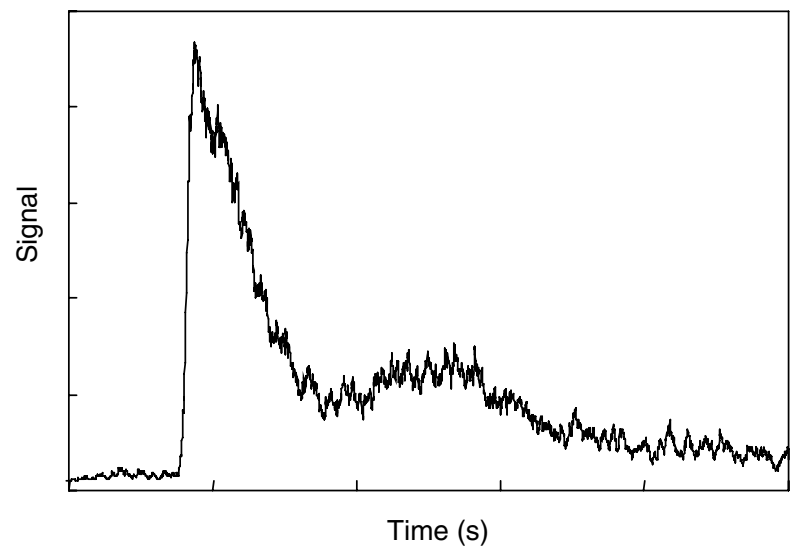

Figure 16

Experimental vapor overhead line response when diplegs are unsubmerged.

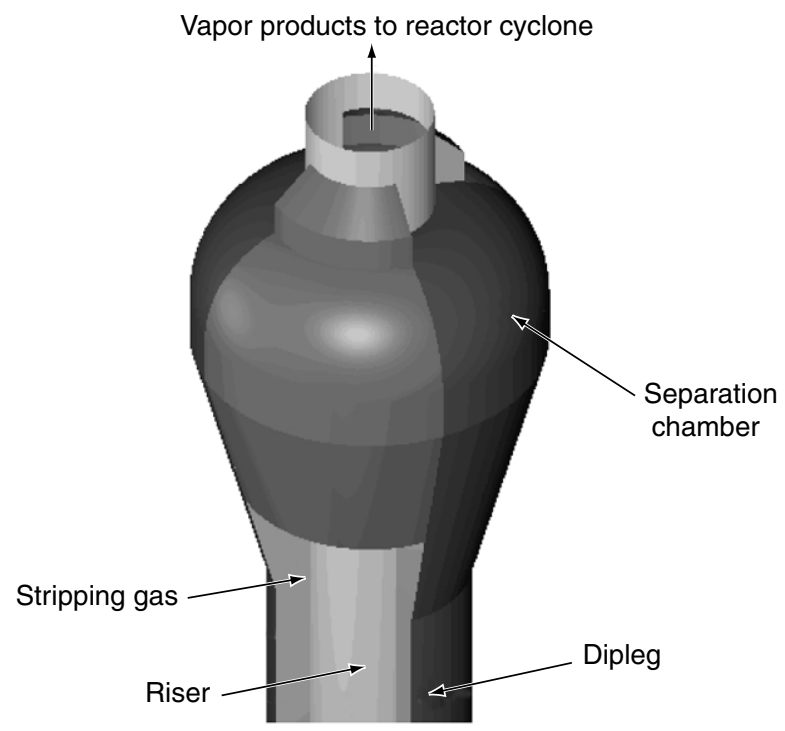

Figure 18

New integrated RSS design.
The IFP catalyst cooler was developed in association with Babcock Entreprises with the following guidelines: maximizing heat-transfer coefficient and providing operation flexibility, minimizing thermal stress, minimizing the possibility of bundle erosion and vibrations [14]. For FCC applications involving heat removal from the regenerators, thermal stress must be minimized in the mechanical design of the heat exchanger; stress is a particularly important problem considering that the exchanger's cooling side is at high pressure (40 to 60 bar) and relatively low temperature (250 to $275^{\circ} \mathrm{C}$ ) while, on the regenerator side, the pressure is low (approximately 2 to 3 bar) but the temperature may be as high as $700-750^{\circ} \mathrm{C}$. For FCC operations, the flexibility is an important issue. Indeed, the refiner may need to process different feed qualities from day to day. The catalyst cooler design must therefore handle rapid cycling on/off and effective adjustments from 0 to $100 \%$ of the design duty.

The bundle design could benefit from an important development previously conducted by Babcock Entreprises for another application. Each tube has a helical shape that enables easy absorption of thermal expansion. The bundle is composed of several helical tubes (Fig. 19), each of which is 
connected to water or steam distributors and collectors that enable optimum gas-liquid flow distribution.

Development was conducted in two steps [14]. First, a preliminary study was conducted to evaluate the parameters that would affect heat transfer on helical tubes at the bench scale. Based on the results of the study, a large-scale bundle $\left(12 \mathrm{~m}^{2}\right)$ was designed in collaboration with Babcock and inserted in the withdrawal well of a large mockup unit (one tenth the size of an industrial unit) at IFP to evaluate temperature profiles and determine scale-up criteria.

The bench-scale Plexiglas model featured a 0.3 meter diameter fluidized bed having an independently fluidized zone as shown in Figure 20. The catalyst was heated to about $80^{\circ} \mathrm{C}$ by steam in the fluidized bed and cooled in the catalyst cooler $\left(0.1 \mathrm{~m}^{2}\right)$ section with water. The water Reynolds number in the catalyst cooler was high enough so that in most cases, heat exchange was governed by the external heat-transfer coefficient. Water temperatures were recorded to determine the heat duty and temperature profiles along the heat exchanger were noted to evaluate the heat-exchange coefficient. The catalyst circulation from the fluidized bed to the cooler could be promoted by two ways (Fig. 20):

- fluidization of the catalyst cooler (backmixing mode);
- independent circulation loop with standpipe and lift at the bottom of the catalyst cooler (flow-through mode).

Studies conducted using this bench-scale unit enabled testing of the following parameters: bundle arrangements, effect of fluidization, effect of catalyst circulation rate, effect of catalyst circulation mode (flow-through or backmixing mode).

This led to design criteria which afford the best solution to remove heat. Conditions were found where fluidization had only a small effect on heat transfer. Also, an important conclusion was that, in order to promote significant catalyst circulation in the backmixing mode, high fluidization velocities were required. For low fluidization velocities, the catalyst circulation was insignificant, leading to highly cooled catalyst and therefore very low duties. In the flowthrough mode, the tube bundle arrangement required only low fluidization rates for good heat-exchange coefficients; therefore, it was concluded that it is much more advantageous to use the flow-through mode to promote high overall duty and heat-transfer rate independently.

These conclusions were clearly confirmed during the large scale study. A semi-industrial $12 \mathrm{~m}^{2}$ tube bundle designed with Babcock Entreprises and based on knowledge gained

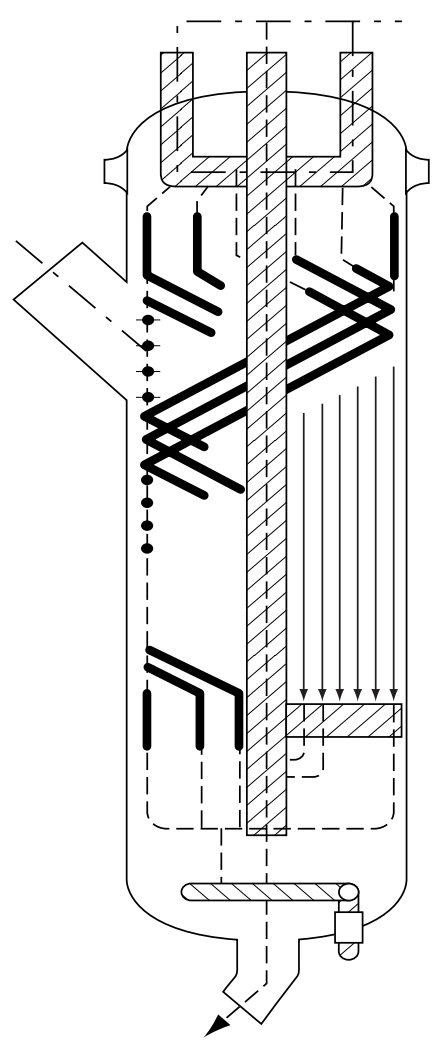

Figure 19

Tube bundle design.

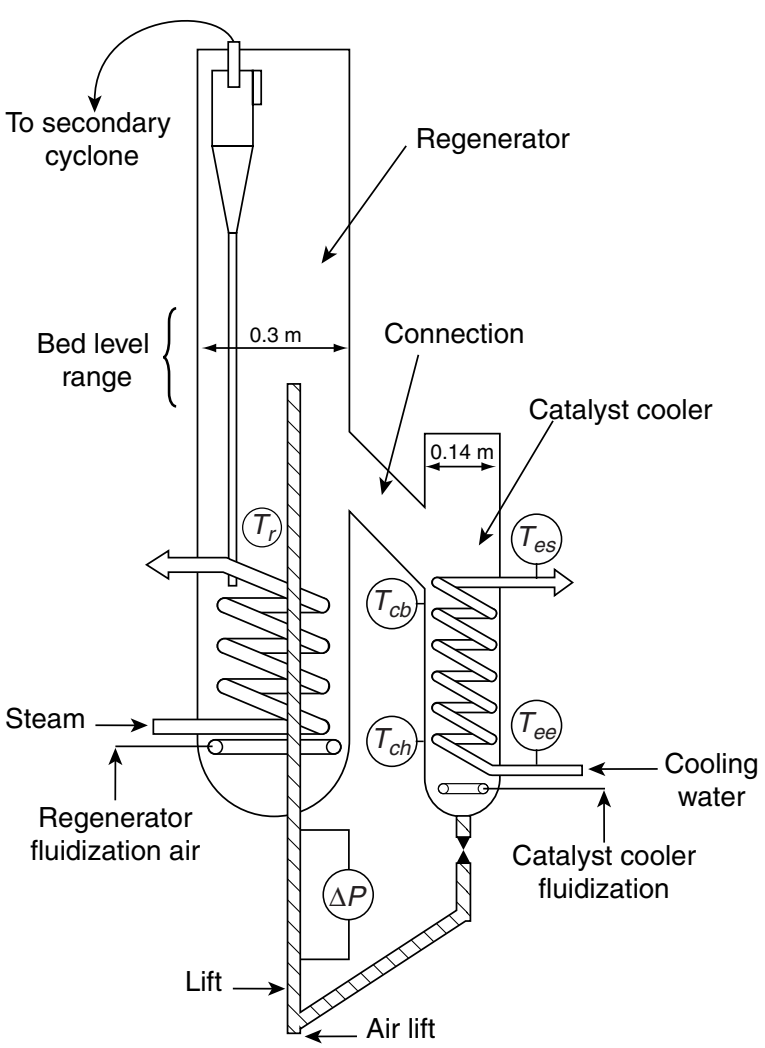

Figure 20

Small-scale study of heat exchange on catalyst cooler bundle. 
from the small-scale experiments was tested. This heat exchanger incorporated important features of industrial units such as cooling fluid distribution and collection. It was inserted in the regenerator withdrawal well on the IFP large mockup unit (Fig. 21). Catalyst was heated up to $80^{\circ} \mathrm{C}$ in the mockup, and cooled with cold water in the catalyst cooler. The large equipment size enabled more than 20 temperature probes to be inserted at various axial and radial locations in the catalyst cooler bundle. With much more local information available than in the small catalyst cooler model, it was possible to confirm the tube bundle performance as a function of representative operating conditions. It was therefore possible to carefully study the heat-transfer rate, the heat-exchange coefficient, the catalyst temperature profiles in the bundle, etc., as a function of the circulation mode, circulation rate and fluidization rate. We could also evaluate the effect of the catalyst inlet position relative to the tube bundle by using two different transfer lines from the regenerator to the catalyst cooler. The results obtained on the large-scale $12 \mathrm{~m}^{2}$ tube bundle were perfectly compatible with the results obtained on the $0.1 \mathrm{~m}^{2}$ tube bundle, making it possible to extrapolate results with complete confidence.

The heat-exchanger duty as a function of the superficial fluidization velocity in the catalyst cooler vessel for both flow-through catalyst circulation and backmixing circulation modes are shown in Figure 22. The figure shows that the duty depends strongly upon the catalyst circulation mode employed. As in the bench-scale unit, the relatively flat curve for the flow-through mode shows little effect of fluidization velocity on heat duty, whereas the greater slope of the backmixing mode data indicates a greater dependence of the duty on gas fluidization velocity. This is because, in the backmixing mode, the "natural catalyst circulation" is a function of the fluidization velocity, whereas in the flowthrough mode, the catalyst circulation is set independently by the operator, therefore the duty can attain a much higher value, even at low fluidization velocity.

In $\mathrm{R} 2 \mathrm{R}$ units, the catalyst cooler can be installed in different configurations. One option is to transfer the catalyst from the second regenerator, Reg 2, to a withdrawal well in which the tube bundle is installed (Fig. 2). The cooled catalyst flowing from the withdrawal well is returned to the first stage regenerator, Reg 1. Usually, the elevation difference between the first and second stages is sufficiently high; no additional lift is required to reintroduce catalyst into the regeneration zone. Therefore, catalyst flows by gravity through the cooling system, increasing only the lift catalyst flow from the first regenerator to the second. The heat removed is then divided between Reg 1 and Reg 2, depending on the temperature of each stage. This solution is particularly suited when the $\operatorname{Reg} 1-\operatorname{Reg} 2$ temperature difference is compatible with the temperature difference that can be matched through the heat-exchange in the catalyst cooler. In such a case, temperature disturbances that could appear when

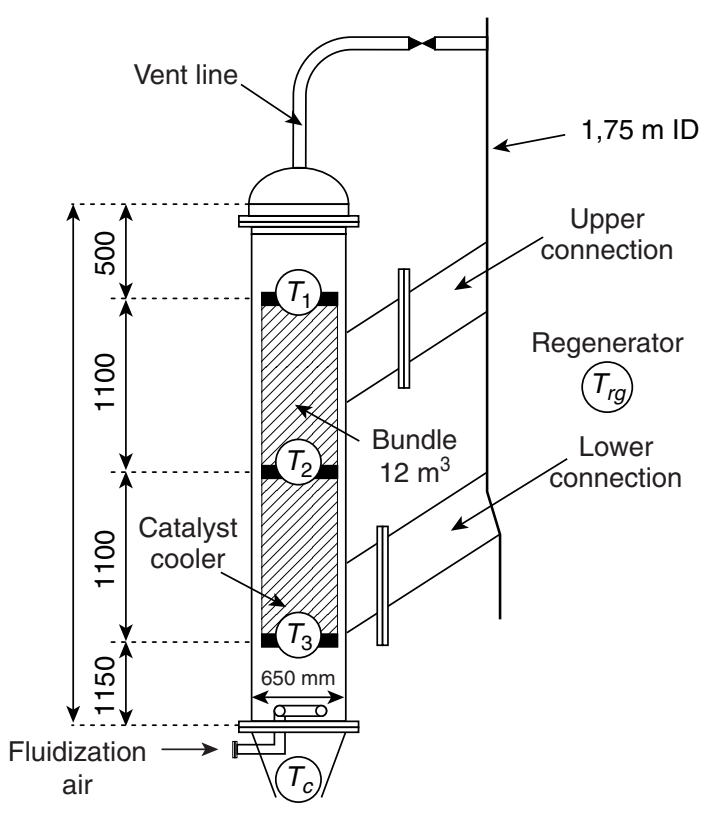

Figure 21

Large-scale study of heat exchange on catalyst cooler bundle.

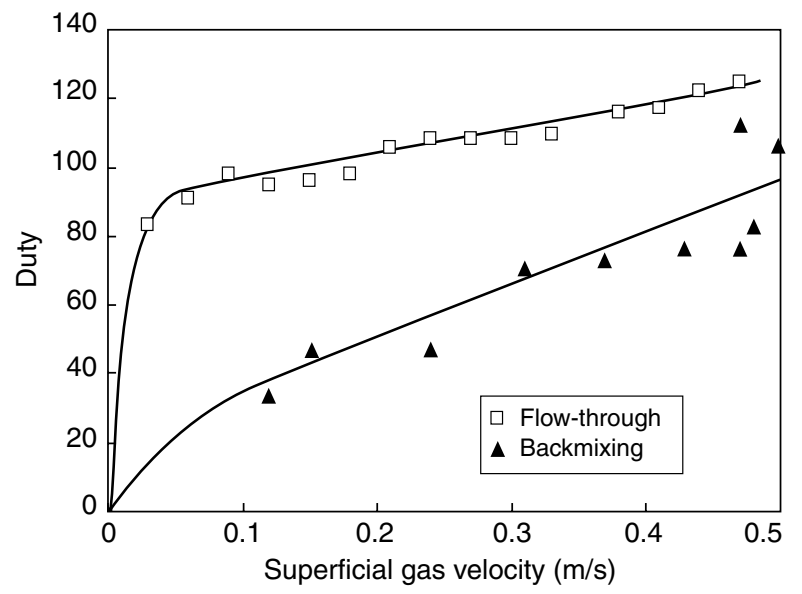

Figure 22

Duty as a function of fluidization velocity for different catalyst circulation modes at large scale.

returning the "cold catalyst" to the regenerator are minimized. An alternative is to take the catalyst from one regenerator and to return it to the same regenerator using an external lift. This solution is very well suited for all single-stage unit revamps.

For both options, catalyst arrives on the top of the tube bundle and exits at the bottom of the withdrawal well (flowthrough mode). The catalyst flow is controlled independently by a slide valve which can be installed in the standpipe at the 
bottom of the catalyst cooler. This provides the most effective way to control the heat duty: when the valve is almost closed, there is very little catalyst circulation and the catalyst temperature drops along with heat transfer in the tube bundle. At high catalyst circulation, the catalyst temperature increases in the tube bundle and, consequently, heat transfer increases. This mode of control of the duty through catalyst circulation is reliable and independent of the fluidization state. The control loop provides a high degree of operating flexibility. Unlike other catalyst cooler designs, the duty can almost vary from zero to the maximum duty without problem.

IFP licensed an $\mathrm{R} 2 \mathrm{R}$ unit to SsangYong, designed to crack a very heavy feed with an estimated $8 \%$ Con $\mathrm{C}$, which even the two-stage regeneration $\mathrm{R} 2 \mathrm{R}$ would not have been able to process. Therefore, the new catalyst cooler technology was incorporated in the design. The unit started up in March 1997 and the operator was satisfied with the catalyst cooler operation. The data collected during the first three months of operation enabled a better evaluation of the tube bundle performance. These conditions provided the client with good operating flexibility and it was easy to meet heat duty requirements by opening or closing the catalyst circulation valve located in the external standpipe, recycling catalyst to the first stage regenerator. As expected, the client needed merely to maintain low fluidization air rates to obtain good heat-exchange. Typical superficial fluidization velocities within the tube bundle were around $0.10 \mathrm{~m} / \mathrm{s}$, as expected.

Figure 23 shows the heat duties that were achieved in April 1997. As seen, the duty varies in a range of approximately 1 to 30 , essentially based on catalyst circulation variations. The implemented design provides flexibility. From the R\&D work, it was possible to model the catalyst cooler operation and compare predicted results with actual data. Figure 23 compares measured and modeled duties showing satisfactory agreement.

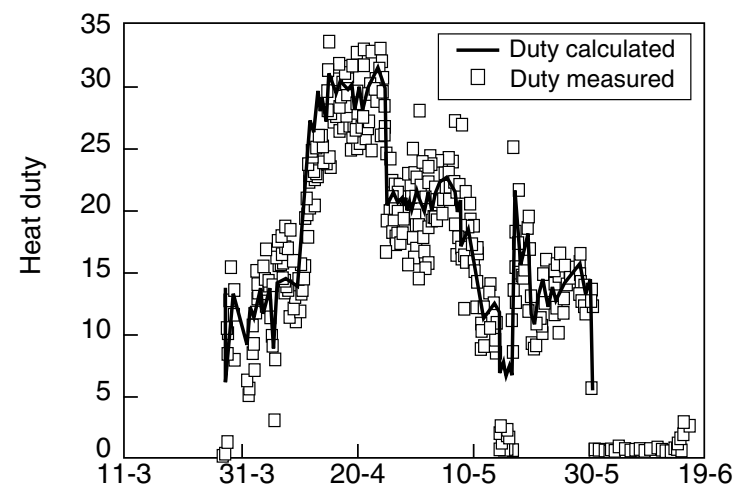

Figure 23

Industrial operation of the first catalyst cooler in operation.

\section{CATALYST CIRCULATION}

It is essential to provide a good and smooth catalyst circulation in FCC units in order to properly conduct catalytic reactions in the riser in stable conditions. Furthermore, catalyst enables coke and heat circulation. For Group A powders such as those used in FCC, it is possible to transport catalyst downward in vertical tubes (standpipes) in a dense phase while maintaining a fluidized state. Standpipes are essential to generate static head required to match the FCC loop pressure balance. Several parameters impact on the behavior of the gas-particle suspension during transport in standpipes, including particle properties, mechanical design of the transfer system and operating conditions. In order to provide smooth catalyst circulation, some important phenomena have to be addressed [15]:

- withdrawing catalyst from a well fluidized zone;

- controlling bubble flow direction;

- maintaining catalyst fluidization throughout the entire system.

The most critical element of standpipe operation is the fluid condition of the catalyst entering the transport system. Catalyst withdrawal from the FCC regenerator is typical of highly aerated catalyst withdrawn from a highly bubbling bed. Upon entry to the standpipe, excess gas (bubbles) must disengage. Ideally, catalyst should enter the standpipe near minimum bubbling conditions.

This can either be achieved within the vessel through an enlarged entry zone into a standpipe, or by withdrawal into a separate vessel, called a withdrawal well (WW), where degassing can occur. Catalyst flow in the WW barrel should be slow enough for bubbles to rise back to the regenerator through the WW vent line.

There are many examples in the literature to show that, if catalyst is not withdrawn from a well fluidized zone, severe circulation problems may occur [16]. We have made a critical experiment in the IFP's large, cold flow test loop to investigate this phenomenon. The test loop [11] contains a withdrawal well (WW) system equipped with several transducers close to the air ring distributor (Fig. 24). The pressure drop or head gain was measured as a function of the WW superficial gas velocity under conditions of good and poor fluidization in the regenerator vessel (Fig. 24). The apparent density of the suspension could then be deduced from the time average $\Delta P$ measurements. As shown in Figure 25, when the regenerator is well fluidized, the apparent density of the suspension in the WW is around $600 \mathrm{~kg} / \mathrm{m}^{3}$ which likely indicates properly fluidized flow down to $1 \mathrm{~cm} / \mathrm{s}$. However, when the air rate in the regenerator is drastically reduced (below $2 \mathrm{~cm} / \mathrm{s}$ ) resulting in poor fluidization, the WW apparent densities exhibit a much different flow behavior shown in Figure 26. Densities obtained with transducer B located closer to the transfer line $(\triangle P B)$ are still similar to the ones obtained when the 


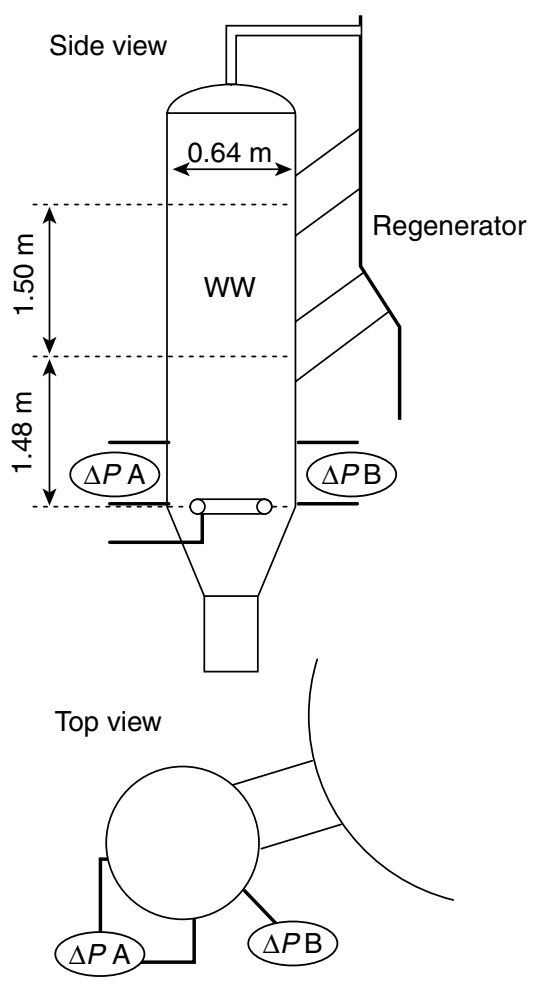

Figure 24

Withdrawal well experimental setup.

regenerator is well fluidized (Fig. 25) but densities obtained with transducer A are much lower, which is not consistent with a properly fluidized flow in the WW.

The difference in apparent densities, from one side of the WW to the other, at such poor fluidization conditions in the regenerator, indicates non-uniform flow within the WW. Poor fluidization in the regenerator results in the flow of partially deaerated solids into the WW. Surprisingly, under these conditions, the air ring, which is almost a perfect distributor ( $100 \times 5 \mathrm{~mm}$ holes in a small $640 \mathrm{~mm}$ ID vessel), could not provide uniform reaeration of the solids. The catalyst used during these experiments had the following properties: $d_{P 50 \%}=72 \mu \mathrm{m}$ with a $16 \%$ fines content below $44 \mu \mathrm{m}$. This experiment demonstrates the importance of catalyst withdrawal in a well fluidized state. It shows as well that refluidizing a defluidized catalyst can be difficult at large scale with industrial distributors.

As discussed for riser separator diplegs, whenever bubbles exist in the bed, they may either flow upward or downward, depending upon their relative velocity compared to the catalyst:

- upward bubble flow: $\quad U_{s}<U_{b r}$

- downward bubble flow: $U_{s}>U_{b r}$

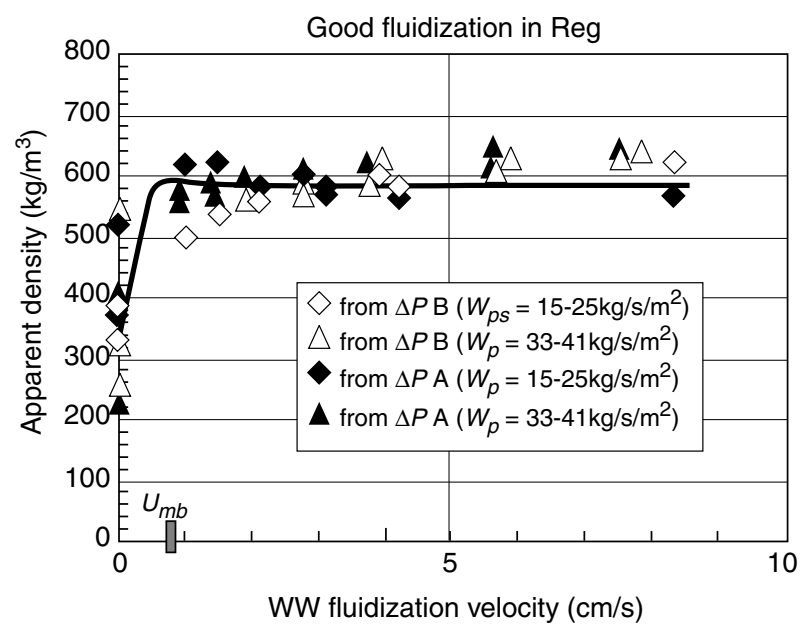

Figure 25

Withdrawal well pressure recovery as a function of operating conditions.

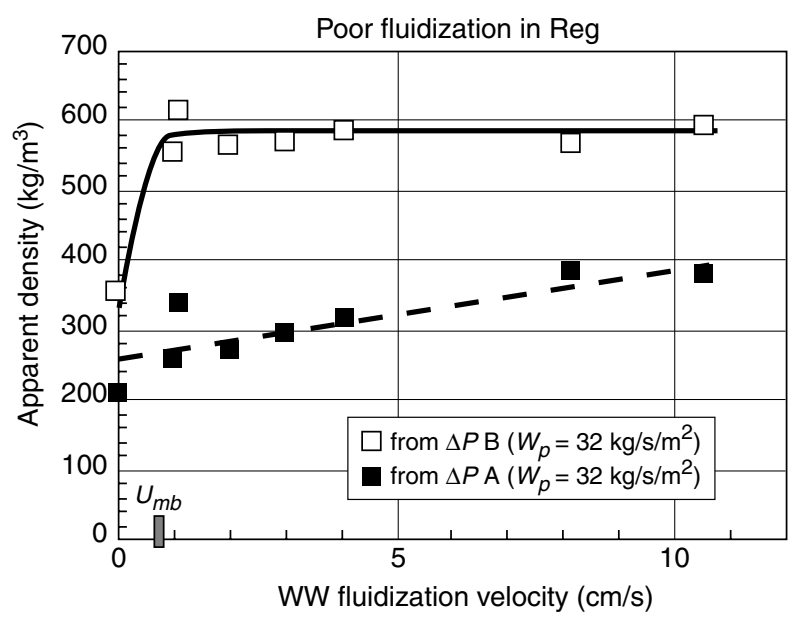

Figure 26

Withdrawal well pressure recovery as a function of operating conditions.

When catalyst velocity $U_{s}$ equals bubble rise velocity $U_{b r}$, bubbles tend to stagnate and then to coalesce, which results in unstable flows.

During catalyst withdrawal from a bubbling bed, it is essential to control the bubble flow. If stable operation is desired, bubbles should not be entrained into the standpipe. With internal systems, the standpipe entry should be enlarged, resulting in a low catalyst downward velocity to disengage bubbles. This is the same for WW systems. The WW barrel is designed to disengage bubbles prior to the standpipe entrance. Downstream, the standpipe essentially operates in a dense phase mode, free of bubbles entering 
from the top. The catalyst velocity is then great enough and any bubble (from aeration taps) should normally be entrained downward.

When a suspension of catalyst flows downward, it is well established that some gas is entrained with the catalyst. Depending on the slip velocity between catalyst and gas, various regimes can be observed [17]:

- non-fluidized flow: $\quad 0 \leq U_{s l} \leq U_{m f}$

- homogeneous fluidized flow (without bubbles):

$$
U_{m f} \leq U_{s l} \leq U_{m b}
$$$$
\text { - bubbling fluidized flow: } \quad U_{m b} \leq U_{s l}
$$

In fluidized downward flow, the catalyst develops static head. As pressure increases however, gas is compressed, leading to changes in the fluidization state of the catalyst. If the gas is too much compressed, flow limitations may occur as a result of defluidization. In order to avoid such phenomena, aeration gas is usually added along the standpipe to compensate for gas compression. At high catalyst mass fluxes, the hypothesis that catalyst and gas flow at the same velocity (i.e. $U_{s l}=0$ ) is usually made $[18,19]$. The "no-slip" theory is essentially valid when $U_{s l}$ is small compared to the catalyst velocity $U_{s}$. This is the case in most FCC standpipes, where typical catalyst velocities are about 1 to $2 \mathrm{~m} / \mathrm{s}$ compared to $U_{m b}$ values in the range 0.5 to $2 \mathrm{~cm} / \mathrm{s}$. Aeration flow rates and spacing can then be determined $[18,19]$.

For low catalyst mass flux systems, slip velocity should not be neglected. In FCC, this is particularly relevant for the WW barrel section and the bottom of the stripper (below the bottom steam distributor) where the catalyst mass flux is relatively low. Therefore, a new procedure taking into account slip velocity in order to evaluate the rate of degassing and the defluidization length at low catalyst mass flux was developped (it is presented in Appendix B).

This procedure was applied to industrial conditions for a $1.3 \mathrm{~m}$ ID barrel with the following catalyst properties: $V_{m f}=1.1 \mathrm{~mm} / \mathrm{s}, V_{m b}=3.3 \mathrm{~mm} / \mathrm{s}, \rho_{m f}=860 \mathrm{~kg} / \mathrm{m}^{3}$ and $\rho_{m b}=800 \mathrm{~kg} / \mathrm{m}^{3}$. Figure 27 shows defluidization length as a function of catalyst mass flux for various gas densities typical of an FCC unit. In Figure 28, we have simulated a change in catalyst properties by changing $U_{m b} / U_{m f}$ from 2.1 to 2.8 .

At fluxes above $200 \mathrm{~kg} / \mathrm{s} / \mathrm{m}^{2}$ (Figs. 27 and 28), catalyst circulation does not significantly affect defluidization length (slip velocity is effectively negligible). Below this value however, the defluidization length strongly decreases as a function of catalyst mass flux due to the increasing importance of the slip velocity. As shown in Figure 27, the defluidization length is almost proportional to gas density. Thus, the lower the pressure, the shorter the defluidization length. Computations suggest that defluidization length strongly increases with the change in $U_{m b} / U_{m f}$, as expected [20].

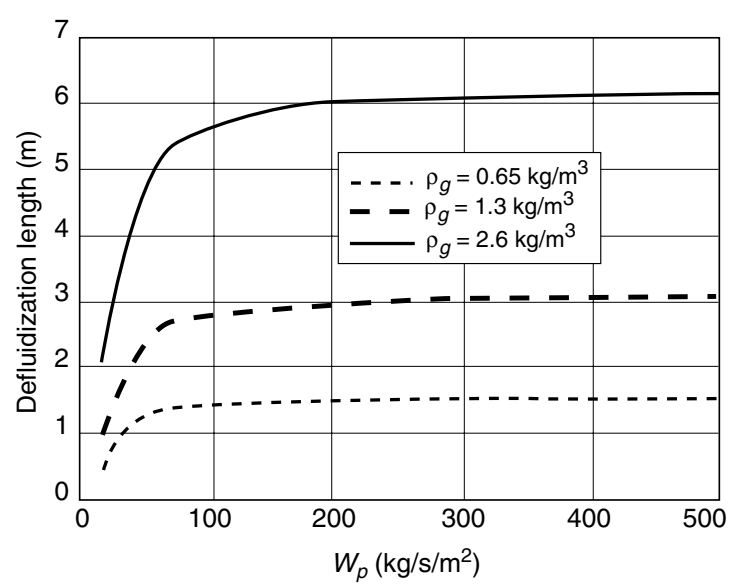

Figure 27

Defluidization length as a function of catalyst mass flux for various gas densities.

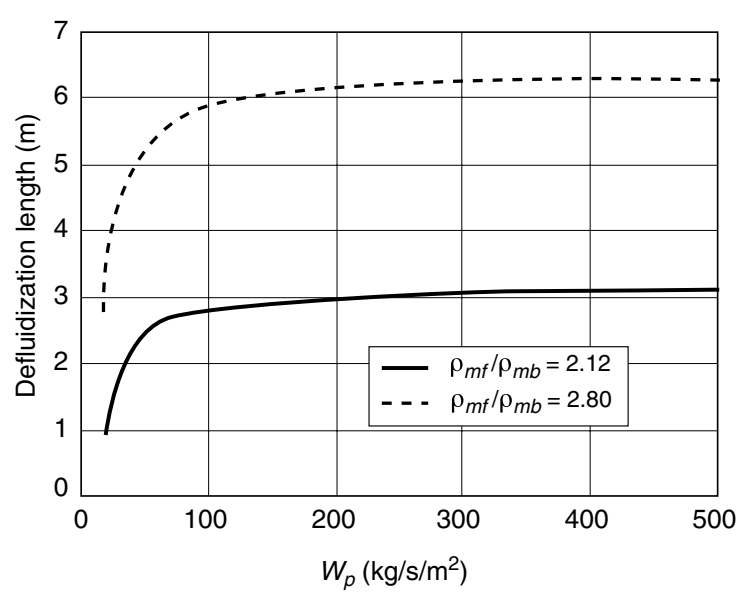

Figure 28

Defluidization length as a function of catalyst mass flux for various catalyst properties.

This theory appears to provide, at least qualitatively, useful information to quantify the defluidization length. Its main disadvantage is probably that the theory requires a lot of information regarding catalyst, which is not often available. Accurate correlations enabling $\rho_{m f}$ and $\rho_{m b}$ predictions as a function of particle and gas properties in industrial conditions are unfortunately not available in the literature.

\section{BASIC RESEARCH IN THE FIELD OF FLUIDIZATION AND TRANSPORT}

Although more than $300 \mathrm{FCC}$ units operate around the world, it is still very difficult to theoretically predict gasparticle interactions which govern fluidization and transport. 
Five years ago, at the International Conference on Fluidization organized by the Engineering Foundation in Tours, France, an open workshop was proposed to compare predictions of models with benchmark experiments. None of the models could accurately predict the flow development of particles in circulating fluidized beds under various operating conditions.

Over the last ten years, development of computers has lead to new computational fluid dynamics possibilities for multiphase flows [21]. Navier-Stokes equations can now be solved for multiphase flows in complex geometries. In order to properly simulate gas-particle flow, Navier-Stokes equations need an appropriate description of gas-particle and particle-particle interactions and extended knowledge of turbulence in multiphase flow. Most of those terms are unfortunately still not available at present and predictive computation remains a difficult task, particularly for Group A powders such as FCC catalyst where interparticle forces may play an important role on the flow structure. To compute gas-particle flow structures with CFD, two approaches (Lagrangian and Eulerian) can be usually adopted. The Lagrangian approach involves the computation of each particle trajectory in a flow field of gas. This approach is not yet adapted to fluidized bed nor riser flow, due to the almost infinite number of particle trajectories to be computed which surpasses computation possibilities. The Eulerian approach is therefore usually adopted. In this case, the particles are supposed to behave like a fluid. This approach requires however an averaging of probability distribution functions for each of the particle properties to go from the particle scale to the CFD flow cell scale. Several unknowns remain and a lot of efforts need to be addressed in this field in order to establish rigorous models and propose physical laws describing gas-particle interactions and mathematical averaging.

CFD models were tested on commercial softwares in order to compute fluidized bed hydrodynamics and riser flow for Group A powders [22, 23]. A good qualitative agreement can be reached between unsteady simulations and experimental flow observations. Rising bubbles (or gas pockets) can be observed in a fluidized bed (Fig. 29) and radial particle segregation (at least partly initiated by the riser termination) can be observed in risers.

However, when quantitative comparisons are conducted to compare simulations to experiments, it is clear that the CFD simulations can only be considered as a qualitative tool. For instance, in Figure 30, we compare average gas holdup in an FCC fluidized bed obtained by simulation and bed expansion tests. One can see that the CFD overpredicts the gas holdup. Gas holdup of $90 \%$, that, in reality, can only be found in transport regimes, are obtained at low fluidization velocities of 10 to $20 \mathrm{~cm} / \mathrm{s}$ which correspond to moderate bubbling regimes.

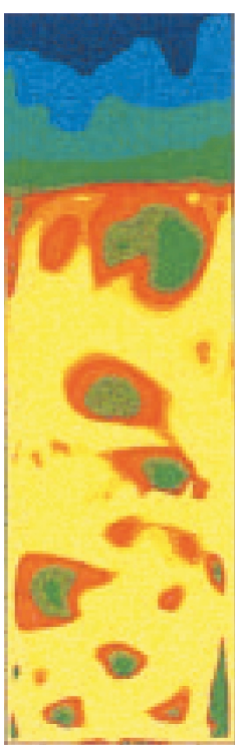

Figure 29

Unsteady CFD simulation of FCC fluidized bed $(D=0.5 \mathrm{~m}$, $\left.V_{s g}=0.2 \mathrm{~m} / \mathrm{s}\right)$.

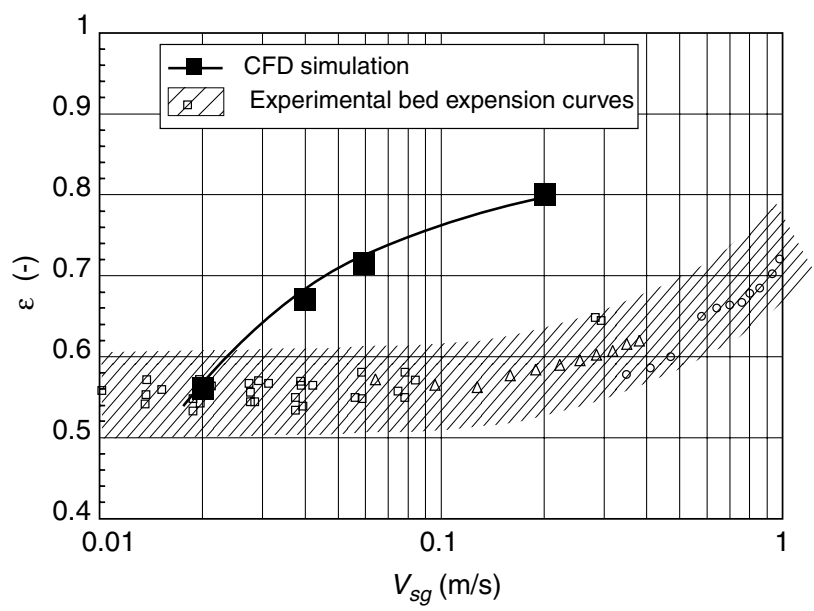

Figure 30

Bed expansion predicted by CFD compared with experimental bed expansions.

CFD progress can then be achieved through two approaches:

- theoretical studies of complete interactions terms at the particle scale and rigorous averaging of those terms for Eulerian simulation. This long-term tremendous effort is underway in several research groups;

- empirical modifications of existing models in order to more quantitatively predict the flow structures. This approach is effective for short-term development 
but requires appropriate data to modify and validate the models. Furthermore, extrapolation is then more difficult.

In this case, to improve the model, the drag force was empirically modified to better represent the bed expansion. The model was then used to study catalyst flow distribution at the bottom of an FCC riser. It was then a useful tool to confirm and solve the specific problem encountered [24].

To evaluate in more detail the results of CFD simulations, local measurements are required in order to provide detailed information on the flow structure. The flow properties (gas hold-up, gas and particle velocities and particle concentration) indeed vary significantly as a function of time and radial and axial locations. Non-intrusive methods can be used such as X-ray [25] or gamma-ray measurements [11]. Intrusive methods, using optical fibers for instance [26-28], are usually less expensive but very complex too. Such measurements require long development due to their specificity in order to adapt the measurement method to the inherent gas-particle constraints and usually complex data postprocessing is required to get valuable and useful data.

Recently, we investigated the flow structure of bubbles in a turbulent FCC fluidized bed operating at high gas velocities $(0.2$ to $2 \mathrm{~m} / \mathrm{s})$ to cover the range of conditions that can be encountered in an FCC fluidized bed regenerator. A $20 \mathrm{~cm}$ ID fluidized bed was used for this study in cold flow conditions [28]. An optical fiber probe was adapted and used in order to determine bubble holdup and velocities at various axial and radial locations along the bed. Long signalprocessing development was required in order to get representative mean values of the bubble properties flowing in the bed [29]. One of the results of this study is the wide scatter in bubble flow properties. As expected, the flow is fairly unsteady. Figure 31 shows the velocity distribution of bubbles detected in the center of the bed in the distributor vicinity during the $160 \mathrm{~s}$ recording period that was required in order to get reproducible means from one experiment to another. Figure 32 shows the bubble hold-up radial profile close to the top of the bed. It is clear that the flow properties are not homogeneous along the bed. More results can be found in [29]. Those results may now help to modify and validate existing CFD models. This effort is presently underway.

CFD is clearly probably a powerful tool that will be more and more used in future development studies. One of its most interesting features is the possibility to simulate flows in complex geometries. However, for reactor-modeling purposes and process simulations, when hydrodynamics is coupled with kinetics and thermodynamics, simpler models such as monodimensional models are also needed. A lot of effort was spent on the kinetic side to predict yields as a function of feed characteristics [30]. However, in most published riser models, the flow calculations are not accurate at all and usually rely on fully empirical correlations. One of the most important reasons is that cross-sectionally averaged drag forces, which govern momentum transfer from particles to gas, are not adapted to the FCC gas-particle flow in riser flow conditions characterized by high particle mass fluxes. As for the CFD simulation of the FCC fluidized bed, when monodimensional Eulerian-Eulerian simulations of gasparticle flow in riser are conducted, a severe reformulation of drag forces is required in order to match the flow development that can be experimentally observed in a riser at high mass fluxes, as shown in Figure 33 where we plotted pressure profiles measured and computed in various flow conditions.

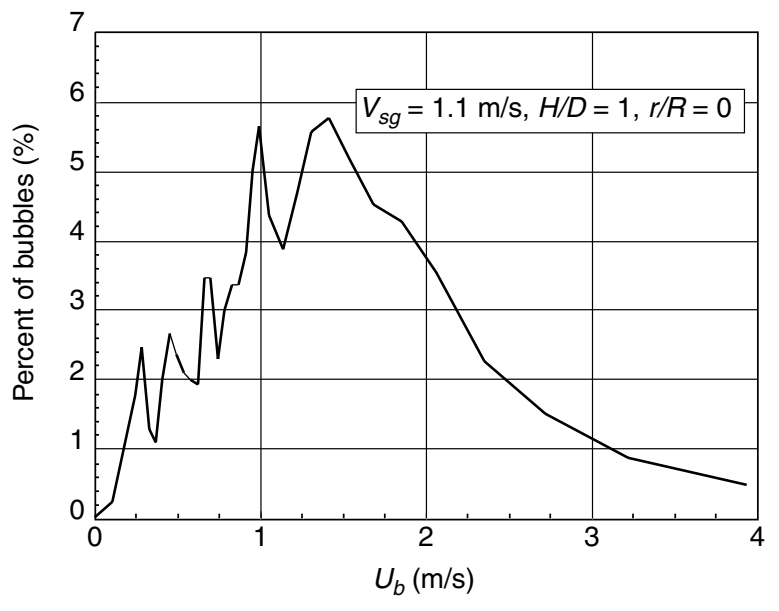

Figure 31

Velocity distribution of bubbles detected during $160 \mathrm{~s}$ with the optical fiber probe in an FCC fluidized bed.

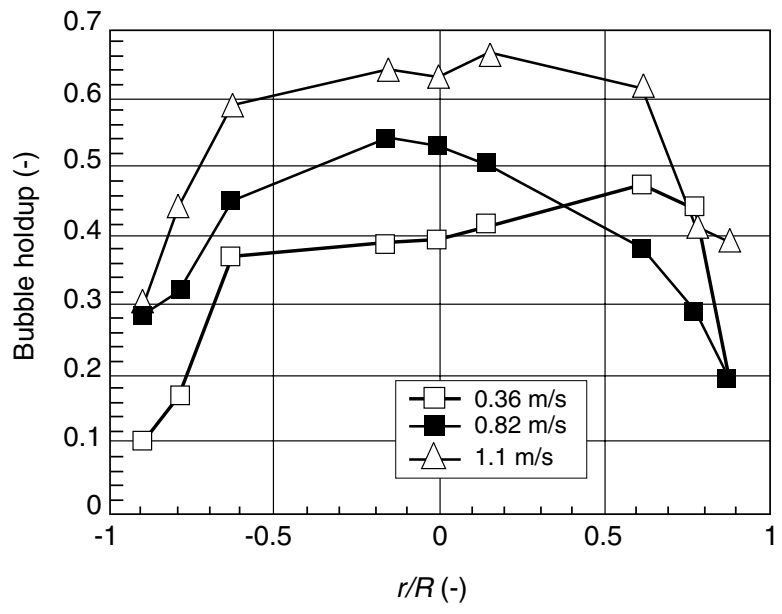

Figure 32

Gas holdup radial repartition in an FCC fluidized bed at $0.8 \mathrm{~m}$ from the distributor. 


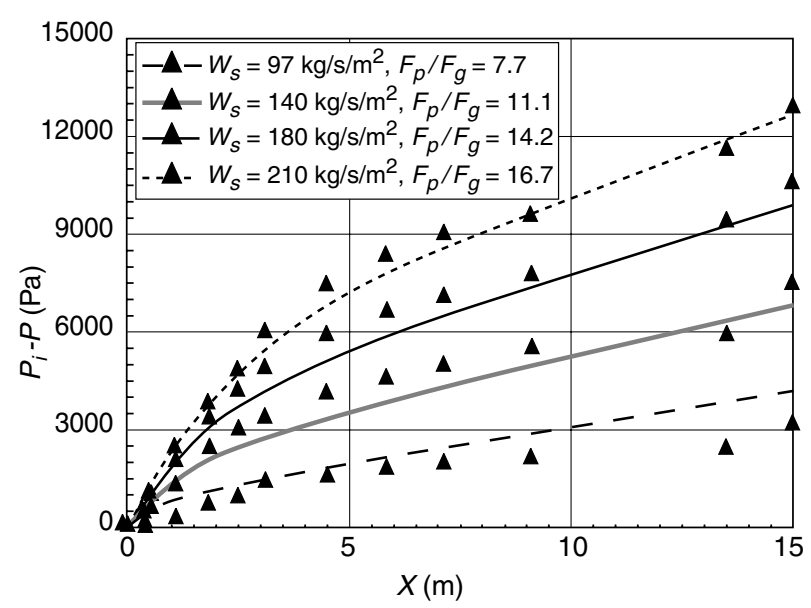

Figure 33

Monodimensional axial pressure profiles measured and predicted along a $0.3 \mathrm{~m}$ ID riser.

\section{CONCLUSION}

Several tools are available for the design and scale-up of technologies in fluidized bed processes such as FCC. Cold flow testing with appropriate measurement methods is useful to study and understand relevant phenomena for scale-up. Over the last years, new emerging simulation techniques such as mutiphase Eulerian simulations in CFD appeared. Those techniques are promising and can already be considered as development tools if they are carefully used. However, basic research is still needed in order to improve the knowledge in the field of gas-particle transport and fluidization.

In this paper, we focussed on development tools required for technology developments with respect to flow phenomena. This is crucial in FCC technology due to the specific nature of the process. Fixed bed pilot plants (microactivity test), circulating fluidized bed pilot plants and process models complete the array of tools that are used to assist in catalyst, testing and new technology developments.

\section{REFERENCES}

1 Avidan, A., Edwards, M. and Owen, H. (1990) Innovative Improvements Highlight FCC's Past and Future. Oil \& Gas J., 88, 2, 33-58.

2 Reichle, A.D. (1992) Fluid Catalytic Cracking Hits 50 Year Mark on the Run. Oil \& Gas J., special issue, May 18 , 41-45.

3 Murphy, J.R. (1992) Evolutionary Design Changes Mark FCC Process. Oil \& Gas J., special issue, May 18, 49-58.

4 Avidan, A. (1992) FCC is Far From Being a Mature Technology. Oil \& Gas J., special issue, May 18, 59-66.
5 Murcia, A.M. (1992) Numerous Changes Mark FCC Technology Advance. Oil \& Gas J., special issue, May 18, 68-71.

6 Jahnig, C.E., Martin, H.Z. and Campbell, D.L. (1984) The Development of Fluid Catalytic Cracking. Chemtech, Feb., 106-112.

7 Dean, R.R., Mauleon, J.L. and Letzsch, W.S. (1982) New Resid Cracker. Oil \& Gas J., special issue, part 1, 80, 40, 7580; part 2, 80, 41, 168-176.

8 Marcilly, C.R. and Bonifay, R.R. (1996) Catalytic Cracking of Resid Feedstocks. Arab. J. Sci. Eng., 21 (4B), 627-651.

9 Johnson, A.R., Letzsch, W.L. and Silverman, M.A. (1994) Upgrade Residues with FCCU's Designed for High Severity Operation. Fuel Reformul., Nov.-Dec., 61-65.

10 Avidan, A.A., Owen, H. and Schipper, P. (1990) FCC Closed Cyclone System. Oil \& Gas J., March 26, 56-62.

11 Galtier, P., Pontier, R. and Patureaux, T. (1989) Near Full Scale Cold Flow Model for the R2R Catalytic Process. Proceedings of the 6th Fludization Conference, Banff, Canada, Engineering Foundation, New York, 17-23.

12 Mauléon, J.L. and Sigaud, J.B. (1987) Mix Temperature Control Enhances FCC. Oil \& Gas J., Feb. 23, 52-55.

13 Heinrich, G., Gauthier, T.A. and Del Pozo, M. (1997) R2R, a Suite of Technologies for Residue Catalytic Cracking. Upgrading Heavy Ends with IFP: 30th anniversary CEDI René-Navarre, IFP, Rueil-Malmaison, France, 113-125.

14 Gauthier, T.A. and Bonifay, R.R. (1999) Catatalytic Cooler Scale-up and Operation. Proceedings of the 2 nd European Congress of Chemical Engineering conference, Montpellier, France, October 5-7.

15 Gauthier, T.A. and Ross, J. (1999) Controling Gas Flow in Standpipe Systems. Proceedings of the 6th International Conference on Circulating Fluidized Beds, Würzburg, Germany, August 22-27, Dechema, Frankfurt am Main, Germany, 483-488.

16 King, D., Forde, R., Leaney P. and Zenz, F. (1989) FCC Cold Modeling Helps Solve FCC Standpipe Flow. Proceedings of the 6th Fluidization Conference, Banff, Canada, Engineering Foundation, New York, 145-152.

17 Jones, P.J. and Leung, L.S. (1985) Downflow of Solids Through Pipes and Valves. Fluidization, 2nd ed., Davidson, J.F., Clift, R. and Harrisson, D. (eds.), Academic Press.

18 Karri, R.S.B. and Knowlton, T.M. (1993) The Effect of Fines Content on the Flow of FCC Catalyst in Standpipes. Proceedings of the 4th International Conference on Circulating Fluidized Beds, Hidden Valley Conference and Mountain Resort Somerset, Pennsylvania, USA, Avidan, A. (ed.), 490-493.

19 Mott, R.W. (1992) Troubleshooting FCC Standpipe Flow Problems. Davidson Catagram, 83, 25-35.

20 Abrahmsen, A.R. and Geldart, D. (1980) Behaviour of GazFluidized Beds of Fine Powders. Powder Technol., 26, 3546.

21 Kuipers, J.A.M. and Van Swaaij, W.P.M. (1998) CFD Applied to Chemical Reaction Engineering. Adv. Chem. Eng., 24, 227-327.

22 Ferschneider, G. and Mège, P. (1996) Eulerian Simulation of Dense Phase Fluidized Beds. Revue de l'Institut français du pétrole, 51, 2, 301-307.

23 Boelle, A. (1997) Validation d'un modèle à deux fluides appliqué à la simulation des lits fluidisés denses. Thèse, Paris VI.

24 Patureaux, T. and Barthod, D. (2000) These proceedings. 
25 Fiorentino, M. and Newton, D. (1998) Application of X-Ray Imaging to Fluidized Bed Scale-up. Proceedings of the 9th Fluidization Conference, Durango, Colorado, Engineering Foundation, New York, 589-596.

26 Werther, J., Hartge, E.U. and Rensner, D. (1993) Measurement Techniques for Gas-Solid Fluidized Beds Reactors. Int. Chem. Eng., 33, 1, 18-26.

27 Herbert, P.M., Gauthier, T.A., Briens, C.L. and Bergougnou M.A. (1994) Application of Optic Fiber Probes to the Measurement of Local Particle Velocity and Concentration in Gas-Solid Flow. Powder Technol., 80, 243-252.

28 Taxil, I.P., Guigon, P., Archimbault, F. and Gauthier, T.A. (1998) Gas Flow Characterization in Turbulent Fluidization for FCC Catalyst. Proceedings of the 9th Fluidization Conference, Durango, Colorado, Engineering Foundation, New York, 69-76.
29 Smith, M., Bayle, J. and Gauthier, T.A. (1999) Bubble Flow Study in a Turbulent FCC Fluidized Bed. Proceedings of the 2nd European Congress of Chemical Engineering Conference, Montpellier, France, October 5-7.

30 Derouin, C., Nevicato, D., Forissier, M., Wild, G. and Bernard, J.R. (1997) Hydrodynamics of Riser Units and their Impact on FCC Operation. Ind. Eng. Chem. Res., 36, 11, 4504-4516

31 Knowlton, T.M., Hirsan, I. and Leung, L.S. (1978) The Effect of Aeration Tap Location on a Non-Mechanical J-Valve. Proceedings of the International Fluidization Conference, Cambridge, Davidson, J.F. (ed.), University Press, Cambridge.

Final manuscript received in January 2000 


\section{APPENDIX A}

Gas flow rate $Q$ entering the riser termination device can either flow in the gas exit $\left(Q_{G}\right)$, either in the particle exit or dipleg $\left(Q_{S}\right)$. The flow repartition between the two gas exits depends upon the pressure difference applied on the two separator's exits.

If $P_{I}$ is the pressure at the separator inlet, it can be written:

$$
\begin{aligned}
& P_{I}-\Delta P_{G}=P_{G} \\
& P_{I}-\Delta P_{s}+\rho_{d} \mathrm{~g} H_{d}-\rho_{b} \mathrm{~g} H_{b}=P_{s}
\end{aligned}
$$

Pressure drop in a separation system typically depends upon the square gas velocity. Therefore, it can be written:

$$
\begin{gathered}
\Delta P_{G}=k_{G} V_{G}^{2}=K_{G} Q_{G}^{2} \\
\Delta P_{s}=k_{s} V_{s}^{2}=K_{s} Q_{s}^{2}
\end{gathered}
$$

The main difference in between both gas and particle exits is that in the gas exit, particle flow is negligible, therefore $K_{g}$ can be assumed to be a constant, whereas in the particle exit, particle flow is high, and as a consequence $K_{s}$ is dependant upon the flow in the particle exit. $K_{g}$ and $K_{s}$ coefficients need to be determined for each separation system. If $U$ is the underflow of gas flowing in the particle outlet, gas mass balance leads to :

$$
Q=Q_{G}+Q_{s}=(1-U) Q+U Q
$$

The combination of Equations (1) to (5) leads to:

$$
P_{G}-P_{s}+\rho_{d} \mathrm{~g} H_{d}-\rho_{b} \mathrm{~g} H_{b}=K_{s} U^{2} Q^{2}-K_{G}(1-U)^{2} Q^{2}
$$

In Equation (6), the unknowns are underflow $U$ and catalyst height $H_{d}$ in the dipleg. Other variables are operating variables (pressures, levels and flow rates) that can be adjusted independently. Both unknowns result from the operating variables. If the pressure at the dipleg outlet $P_{G}$ is far below the pressure applied at the gas exit $P_{g}$, then most of the gas will be forced to the dipleg. No dense phase will form in the dipleg $\left(H_{d}=0\right)$ and dilute gas-solid flow will occur $(U=100 \%)$. On the other hand, if the pressure applied at the dipleg outlet is far above the pressure applied to the gas exit, then no gas except interstitial gas will flow in the dipleg $(U=0 \%)$ and a dense phase will form in the dipleg to counteract the high pressure difference. To solve Equation (6), we need to evaluate underflow $U$ by considering no dense phase $\left(H_{d}=0\right)$ in the dipleg. $U$ is given by the only physical root of Equation (6).

If the solution $U$ is below 0 , this means that the back pressure exerted to the dipleg is excessive. Therefore, a dense zone will form in the dipleg and $H_{d}$ can then be computed with the assumption that $U=0(E q$. (7)). In such a case, gas entrainment through the dipleg is not governed anymore by the separator pressure balance but by dense phase gas entrainment through the dipleg (Eq.(8)). Dipleg flowing density as a function of catalyst circulation needs to be separately estimated:

$$
\begin{gathered}
H_{d}=\frac{P_{s}-P_{G}+\rho_{b} \mathrm{~g} H_{b}-K_{G} Q^{2}}{\rho_{d} \mathrm{~g}} \\
Q_{s}=W_{s}\left(\frac{1}{\rho_{d}}-\frac{1}{\rho_{s k}}\right)
\end{gathered}
$$

\section{APPENDIX B}

The following equations apply in the study of the downward flow of an homogeneous suspension free of bubbles.

The catalyst velocity in the barrel is given by:

$$
U_{p}=\frac{W_{p}}{\rho_{p}(1-\varepsilon)}
$$

The interstitial gas velocity in the barrel is given by:

$$
U_{g}=\frac{Q_{g i}}{A \varepsilon}
$$

Knowing that:

$$
\vec{U}_{s l}=\vec{U}_{g}-\vec{U}_{p}
$$

we can combine Equations (1), (2) and (3) to get:

$$
Q_{g i}=A \varepsilon\left(\frac{W_{p}}{\rho_{p}(1-\varepsilon)}-U_{s l}\right)
$$

Intraporous gas volumetric flow rate is given by:

$$
Q_{g p}=\left(\frac{W_{p} A}{\rho_{p}}-\frac{W_{p} A}{\rho_{s k}}\right)
$$

The amount of gas traveling down in the emulsion is:

$$
Q_{g}=Q_{g i}+Q_{g p}
$$

Equations (4) to (6) show that the amount of entrained gas depends upon the slip velocity and voidage, which are related to fluidization properties.

In the non-fluidized flow regime, particles can rearrange due to their movement. The bed voidage, which can have values between the minimum fluidization voidage $\rho_{m f}$ and the tapped voidage $\rho_{t}$ can be related to slip velocity $[18,31]$ by:

$$
\varepsilon=\varepsilon_{t}+\left(\varepsilon_{m f}-\varepsilon_{t}\right) \frac{U_{s l}}{U_{m f}}
$$

In fluidized flow, it is well accepted that bed expansion between $U_{m f}$ and $U_{m b}$ can be described by a Richardson and Zaki type of equation:

$$
U_{s l}=a+b \varepsilon^{n}
$$

with $n=4.65$ for FCC type particles. 
The constants, $a$ and $b$, can be derived from the catalyst fluidization properties $U_{m f}, U_{m b}, \rho_{m f}$ and $\rho_{m b}$ :

$$
\begin{aligned}
& a=U_{m f}-b \varepsilon_{m f}^{n} \\
& b=\frac{U_{m f}-U_{m b}}{\varepsilon_{m f}^{n}-\varepsilon_{m b}^{n}}
\end{aligned}
$$

Pressure gradients along the flow are required to properly describe the compression effect. In defluidized flows (packed bed conditions), the Ergun equation should apply. For Group A particles, only the viscous term needs to be considered, which after simplification leads to:

$$
\frac{\mathrm{d} P}{\mathrm{~d} x}=\rho_{p}(1-\varepsilon) \frac{U_{s l}}{U_{m f}} \mathrm{~g}
$$

And for fluidized flow:

$$
\frac{\mathrm{d} P}{\mathrm{~d} x}=\rho_{p}(1-\varepsilon) \mathrm{g}
$$

The downward flowing gas is compressed by the head gain. Therefore, it can be written as:

$$
\frac{\mathrm{d}\left(Q_{g} P\right)}{\mathrm{d} x}=0
$$

These equations together provide a complete description of the suspension flow. In order to compute pressure, voidage and slip velocity profiles along the downward flow, a simple procedure was established. The defluidization length can then be deduced from the computed slip velocity profile when $U_{s l}=U_{m f}$. Figure 1 shows the schema of computation to be used.

\begin{tabular}{|l|}
\hline \multicolumn{1}{|c|}{ Input data } \\
Operating conditions \\
$W_{p}=$ catalyst mass flux \\
$T=$ flow temperature \\
$P=$ pressure at inlet \\
Geometrical data \\
$D=$ pipe diameter \\
$H=$ height \\
$\mathrm{d} x=$ increment \\
Fluidization properties \\
$U_{m f}=$ min. fluidization velocity \\
$\rho_{m f}=$ min. fluidization density \\
$U_{m b}=$ min. bubbling velocity \\
$\rho_{m b}=$ min. bubbling density \\
\hline
\end{tabular}

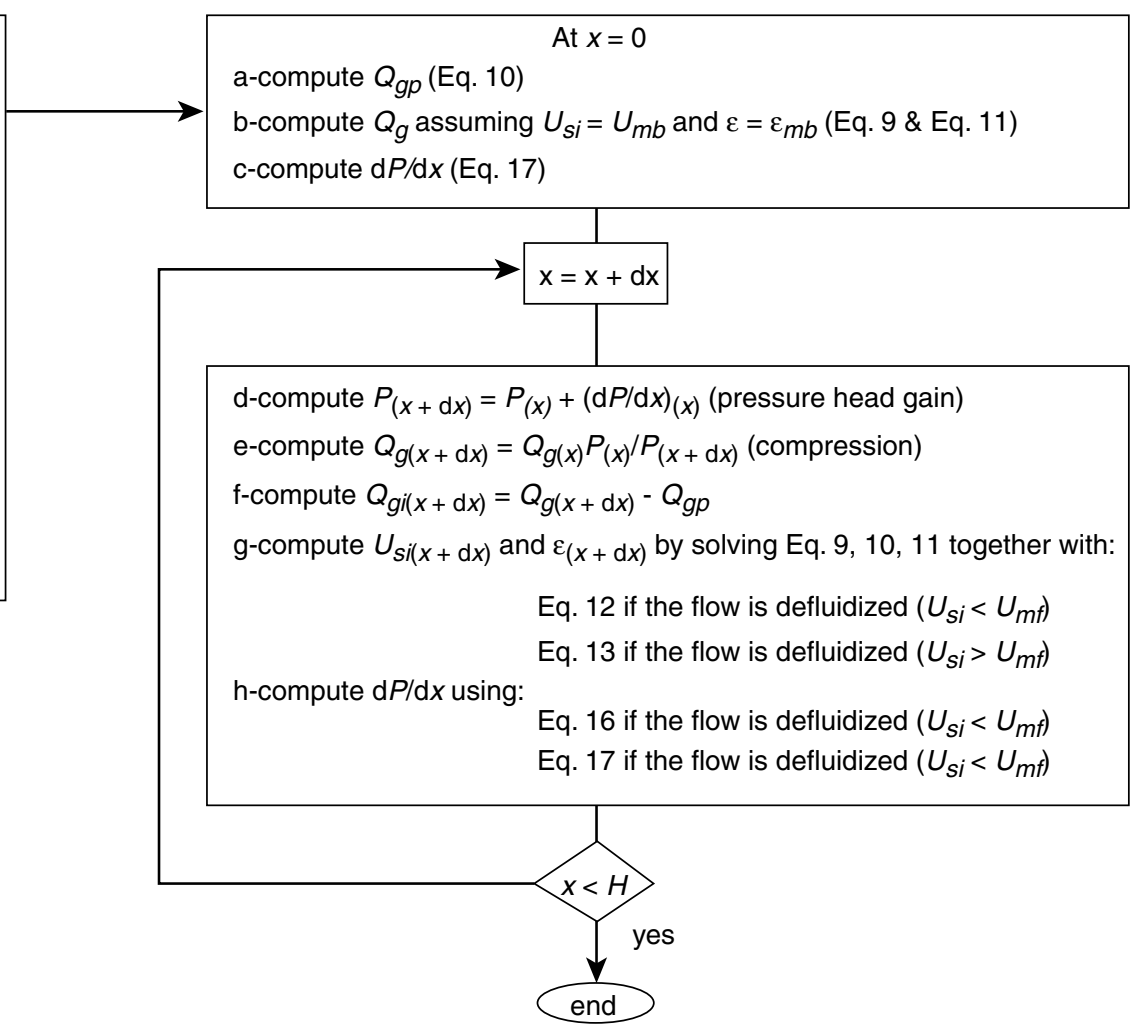

Figure 1

Computation procedure for defluidization. 